\title{
Responses of reactive oxygen species and methylglyoxal metabolisms to magnesium- deficiency differ greatly among the roots, upper and lower leaves of Citrus sinensis
}

\author{
Yan-Tong Cai ${ }^{1}$, Han Zhang ${ }^{1}$, Yi-Ping $\mathrm{Qi}^{2}$, Xin Ye ${ }^{1}$, Zeng-Rong Huang ${ }^{1}$, Jiu-Xin Guo ${ }^{1}$, Li-Song Chen ${ }^{1,3,4^{*}}$ (D) and \\ Lin-Tong Yang ${ }^{1 *}$
}

\begin{abstract}
Background: Magnesium (Mg)-deficiency is one of the most prevalent physiological disorders causing a reduction in Citrus yield and quality. 'Xuegan' (Citrus sinensis) seedlings were irrigated for 16 weeks with nutrient solution containing $2 \mathrm{mM}$ (Mg-sufficiency) or $0 \mathrm{mM}$ (Mg-deficiency) $\mathrm{Mg}\left(\mathrm{NO}_{3}\right)_{2}$. Thereafter, we investigated the Mg-deficient effects on gas exchange and chlorophyll a fluorescence in the upper and lower leaves, and $\mathrm{Mg}$, reactive oxygen species (ROS) and methylglyoxal (MG) metabolisms in the roots, lower and upper leaves. The specific objectives were to corroborate the hypothesis that the responses of ROS and MG metabolisms to Mg-deficiency were greater in the lower leaves than those in the upper leaves, and different between the leaves and roots.

Results: Mg level was higher in the Mg-deficient upper leaves than that in the Mg-deficient lower leaves. This might be responsible for the Mg-deficiency-induced larger alterations of all the measured parameters in the lower leaves than those in the upper leaves, but they showed similar change patterns between the Mg-deficient lower and upper leaves. Accordingly, Mg-deficiency increased greatly their differences between the lower and upper leaves. Most of parameters involved in ROS and MG metabolisms had similar variation trends and degrees between the Mg-deficient lower leaves and roots, but several parameters (namely glutathione S-transferase, sulfite reductase, ascorbate and dehydroascorbate) displayed the opposite variation trends. Obviously, differences existed in the Mgdeficiency-induced alterations of ROS and MG metabolisms between the lower leaves and roots. Although the activities of most antioxidant and sulfur metabolism-related enzymes and glyoxalase I and the level of reduced glutathione in the Mg-deficient leaves and roots and the level of ascorbate in the leaves were kept in higher levels, the levels of malonaldehyde and MG and/or electrolyte leakage were increased in the Mg-deficient lower and upper leaves and roots, especially in the Mg-deficient lower leaves and roots.
\end{abstract}

Conclusions: The ROS and MG detoxification systems as a whole did not provide sufficient detoxification capacity to prevent the Mg-deficiency-induced production and accumulation of ROS and MG, thus leading to lipid peroxidation and the loss of plasma membrane integrity, especially in the lower leaves and roots.

Keywords: Antioxidant, Citrus sinensis, Magnesium (Mg)-deficiency, Methylglyoxal, Reactive oxygen species, Sulfur metabolism

\footnotetext{
* Correspondence: lisongchen2002@hotmail.com; lisongchen@fafu.edu.cn; talstoy@sina.com

${ }^{1}$ Institute of Plant Nutritional Physiology and Molecular Biology, College of Resources and Environment, Fujian Agriculture and Forestry University,

Fuzhou 350002, China

Full list of author information is available at the end of the article
}

(c) The Author(s). 2019 Open Access This article is distributed under the terms of the Creative Commons Attribution 4.0 International License (http://creativecommons.org/licenses/by/4.0/), which permits unrestricted use, distribution, and reproduction in any medium, provided you give appropriate credit to the original author(s) and the source, provide a link to the Creative Commons license, and indicate if changes were made. The Creative Commons Public Domain Dedication waiver (http://creativecommons.org/publicdomain/zero/1.0/) applies to the data made available in this article, unless otherwise stated. 


\section{Background}

Magnesium (Mg), an essential macronutrient for the normal growth and development of higher plants, plays key roles in various biochemical and physiological processes, including chlorophyll (Chl) biosynthesis, gas exchange, and formation and detoxification of reactive oxygen species (ROS) [1-7]. Despite all this, Mg has been neglected by researchers in plant nutrition compared with the other macronutrients [8]. Mg-deficiency is becoming an increasingly serious and urgent problem adversely affecting productivity and quality of many agricultural crops $[9,10]$. In China, Mg-deficiency is one of the most common physiological disorders causing a reduction in yield and quality of Citrus [11, 12].

$\mathrm{Mg}$-deficiency-induced decline in leaf $\mathrm{CO}_{2}$ assimilation is a very common phenomenon occurred in many plants including Citrus [12-17]. A consequence of the decline in photosynthesis in response to $\mathrm{Mg}$-deficiency is that less of the absorbed photon-energy captured by light-harvesting pigments is utilized in the photosynthetic electron transport, so more excess light energy, which can potentially induce the formation of ROS [18], exists in the Mg-deficient leaves [2, 14]. Plants have evolved diverse enzymatic [namely guaiacol peroxidase (GuPX), ascorbate (ASC) peroxidase (APX), superoxide dismutase (SOD), monodehydroascorbate (MDHA) reductase (MDHAR), dehydroascorbate (DHA) reductase (DHAR), glutathione reductase (GR), catalase (CAT) and sulfur (S) metabolism-related enzymes] and non-enzymatic [namely reduced glutathione (GSH) and ASC] detoxification systems to protect cells against oxidative stress due to increased production and accumulation of ROS [18-20]. Antioxidant enzyme system has been considered as the first line of defense against the oxidative stress [21]. Mg-deficiency-induced increases of both antioxidant enzyme activities and antioxidant metabolite levels in leaves have been observed in many plants, including: bean [22, 23], maize [24], wheat [25], mulberry [26], Citrus [2, 14], rice [27, 28], and pepper [29]. There are reports showing that the Mg-deficiency-induced upregulation of both antioxidant metabolites and enzymes may provide sufficient protection to them against oxidative stress, as indicated by the unaltered or decreased malondialdehyde (MDA) level in the Mg-deficient leaves of Citrus reticulata [14], rice [28] and mulberry [26]. However, MDA level was elevated in the Mg-deficient leaves of maize [24], rice [27], Citrus grandis and Citrus sinensis [2] accompanied by enhanced antioxidant capacity.

Thiol-based antioxidant system is the second line of defense against the oxidative damage [21]. Evidence shows that $\mathrm{S}$ metabolism, a core pathway for the biosynthesis of $\mathrm{S}$-containing compounds-namely cysteine (Cys), $\mathrm{GSH}$ and $\mathrm{H}_{2} \mathrm{~S}$, plays crucial roles in plant adaptive responses to abiotic stresses $[19,20,30]$. So far, a few studies have investigated the responses of $\mathrm{S}$ metabolism to nutrient deficiencies. Most of these studies have focused on iron $(\mathrm{Fe})$ and nitrogen $(\mathrm{N})$ deficiencies [31-33]. Very little is known about the Mg-deficiency-induced alterations of $\mathrm{S}$ metabolism in plant leaves. Elevated concentration of GSH (SH-compounds) and/or ratio of GSH/oxidized glutathione (GSSG) have been observed in Mg-deficient leaves of bean [23] and rice [28]. Yang et al. [2] reported that the Mg-deficient C. grandis and C. sinensis leaves had higher GSSG level, lower GSH level and GSH/(GSH + GSSG) ratio, but unaltered (GSH + GSSG) level. The Mg-deficient pepper leaves displayed a relatively lower ratio of GSH/GSSG [29]. Thus, it is reasonable to hypothesize that the activities of $S$ metabolism-related enzymes [i.e., ATP sulphurylase (ATPS), adenosine 5 '-phosphosulfate reductase (APR), Cys synthase (CS), glutathione S-transferase (GST), $\gamma$-glutamylcysteine synthase $(\gamma \mathrm{GCS})$, sulfite reductase $(\mathrm{SiR})$ and $\gamma$-glutamyltransferase $(\gamma \mathrm{GT})]$ might be altered in the Mg-deficient leaves.

Production and accumulation of methylglyoxal (MG, a cytotoxic compound) in plant cells often increases in response to abiotic stresses [20,34,35]. Over-accumulation of MG in plant cells can lead to detrimental effects by promoting ROS generation and inhibiting antioxidant enzyme system $[34,36]$. To mitigate cellular injury caused by increased accumulation of MG, plants have evolved a MG-detoxifying glyoxalase (Gly) system, mainly including Gly I and Gly II. Gly I converts hemithioacetal (HTA), formed spontaneously from MG and GSH, to S-D-lactoylglutathione (SLG). SLG is then hydrolyzed to D-lactate by Gly II and one molecule of GSH is recycled back in the Gly system. Thus, the availability of GSH plays a key role in the detoxification of MG [33, 34]. Studies demonstrated that several metabolic pathways (i.e., photosynthesis, respiration, glycolysis and membrane lipid peroxidation) involved in the production of MG were affected in the Mg-deficient leaves [2-4, 7, 14, 24]. In a study, Peng et al. [37] observed that Mg-deficiency decreased the abundance of chloroplastic Gly I in C. sinensis leaves. Therefore, the production and accumulation of MG, as well as the activities of glyoxalases should be altered in Mg-deficient leaves.

In Mg-starved plants, $\mathrm{Mg}$ remobilization from the old leaves to the young tissues was increased [38]. Previous studies showed that Mg-deficiency affected pigments, gas exchange, organic acid (OA), protein, amino acid and carbohydrate metabolisms more in the older leaves than those in the younger leaves $[3,39,40]$. This drives us to hypothesize that the Mg-deficiency-induced alterations of ROS and MG metabolism might become more pronounced with increasing leaf age. Few studies 
investigated the Mg-deficient effects on the concentrations of antioxidant metabolites, the activities of antioxidant enzymes, and lipid peroxidation in the leaves of different positions (ages) [29, 40-42], but the results were somewhat inconsistent. In a study with common bean plants, Huang and Chu [40] found that the Mg-deficiency-induced increases of electrolyte leakage, MDA concentration and APX activity were greater in the older primary leaves than those in the younger first trifoliate leaves, and that the activities of SOD, GuPX and CAT were not unaltered in the Mg-deficient primary leaf, but increased in the Mg-deficient first trifoliate leaf except for unchanged CAT activity, demonstrating that ROS metabolism was less affected in the first trifoliate leaf than in the primary leaf. However, Anza et al. [29] observed that the Mg-deficiency-induced antioxidant responses were less in the youngest and the oldest leaves. To our knowledge, very little is known about the Mg-deficient effects on the activities of enzymes related to $\mathrm{S}$ metabolism and MG detoxification in the leaves of different positions (ages).

So far, most of studies have focused on Mg-deficient effects on leaves because Mg-deficiency-induced leaf chlorosis is one of the earliest and the most easily identified symptoms [2, 43], less was known about the Mg-deficient effects on the roots [3, 44]. There are several reports showing that the Mg-deficient effects on anatomy, gas exchange, carbohydrate, $\mathrm{OA}$, amino acid and phenolic metabolisms differ between the roots and leaves [2-4, 6, 7, 45-47]. Transcriptome, proteome and miRNA analyses reveal that the Mg-deficient effects on the expression of genes, proteins and miRNAs involved in carbohydrate and energy metabolism, ROS and MG detoxification, and amino acid and protein metabolisms differ between the roots and leaves [4, 37, 48-51]. Thus, the responses of ROS and MG metabolisms to Mg-deficiency should differ between the leaves and roots.

Here, we investigated the Mg-deficiency-induced alterations of gas exchange and $\mathrm{Chl}$ a fluorescence in the lower and upper leaves, and $\mathrm{Mg}$, ROS production, electrolyte leakage, MDA, MG, antioxidant metabolites, and enzymes involved in ROS and MG detoxification in the roots, lower and upper leaves of $C$. sinensis seedlings. Our specific objectives were to corroborate the hypothesis that the Mg-deficiency-induced alterations of ROS and MG metabolisms were greater in the lower leaves than those in the upper leaves, and different between the leaves and roots.

\section{Methods}

\section{Seedling culture and $\mathrm{mg}$ treatments}

Seedling culture and Mg treatments were performed according to Peng et al. [37] with some modifications. Fifteen week-old seedlings of $C$. sinensis cv. Xuegan in $6 \mathrm{~L}$ pots (two seedlings per pot) containing clean river sand washed thoroughly with tap water were raised in a greenhouse under natural photoperiod at Fujian Agriculture and Forestry University, Fuzhou, China $\left(26^{\circ} 5^{\prime} \mathrm{N}\right.$, $119^{\circ} 14^{\prime}$ E). Each pot were fertilized every 2 day with nutrient solution containing $1 \mathrm{mM} \mathrm{KNO}_{3}, 2 \mathrm{mM} \mathrm{K}_{2} \mathrm{SO}_{4}$, $5 \mathrm{mM} \mathrm{Ca}\left(\mathrm{NO}_{3}\right)_{2}, 1 \mathrm{mM} \mathrm{KH} \mathrm{PO}_{4}, 10 \mu \mathrm{M} \mathrm{H}_{3} \mathrm{BO}_{3}, 2 \mu \mathrm{M}$ $\mathrm{MnCl}_{2}, \quad 2 \mu \mathrm{M} \quad \mathrm{ZnSO}_{4}, \quad 0.5 \mu \mathrm{M} \quad \mathrm{CuSO}_{4}, \quad 0.065 \mu \mathrm{M}$ $\left(\mathrm{NH}_{4}\right)_{6} \mathrm{Mo}_{7} \mathrm{O}_{24}, 20 \mu \mathrm{M}$ Fe-EDTA and $0 \mathrm{mM}$ or $2 \mathrm{mM}$ $\mathrm{Mg}\left(\mathrm{NO}_{3}\right)_{2}$ until some of nutrient solution flowed out of the hole in the bottom of the pot $(\sim 500 \mathrm{~mL})$. To maintain a constant $\mathrm{N}$ concentration, equivalent moles of $\mathrm{NH}_{4} \mathrm{NH}_{3}$ instead of $\mathrm{Mg}\left(\mathrm{NO}_{3}\right)_{2}$ were added in the nutrient solution. Sixteen weeks after Mg treatments, 5-mm-long white root tips, and $\sim 11$-week-old lower (quarter height) and 5-week-old upper (three quarter height) leaves were used for all measurements with the exception of root Mg concentration [3]. Leaves (midribs and petioles removed), leaf disks $(0.6 \mathrm{~cm}$ in diameter) and $\sim 5$-mm-long white root tips were collected from the plants that had been used for the measurements of leaf gas exchange and $\mathrm{Chl}$ a fluorescence at noon in the sunny day. After being frozen immediately in liquid $\mathrm{N}_{2}$, all samples were stored at $-80^{\circ} \mathrm{C}$ until extraction of enzymes, total soluble proteins, antioxidant metabolites, MDA and MG. These unsampled seedlings were used to measure $\mathrm{Mg}$, electrolyte leakage, and superoxide anion and $\mathrm{H}_{2} \mathrm{O}_{2}$ generation.

\section{Root and leaf $\mathrm{mg}$}

The small $(<2 \mathrm{~mm}$ in diameter) first- and second-order fibrous roots [20], upper and lower leaves (midribs and petioles removed) [3] were used for the measurements of $\mathrm{Mg}$. Root and leaf $\mathrm{Mg}$ concentration was measured using PinAAcle 900F Atomic Absorption Spectrometer (PerkinElmer Singapore Pte Ltd., Singapore) [3]. There were 10 replicates per treatment.

\section{Leaf gas exchange and $\mathrm{Chl}$ a fluorescence}

Gas exchange was measured with a portable photosynthesis system (CIRAS-2, PP-Systems, Herts, UK) at a leaf temperature of $27.79 \pm 0.3^{\circ} \mathrm{C}$, a relative humidity of 46.1 $\pm 1.2 \%$, a controlled $\mathrm{CO}_{2}$ concentration of $\sim 380 \mu \mathrm{mol}$ $\mathrm{mol}^{-1}$ and a controlled light intensity of $\sim 1000 \mu \mathrm{mol}$ $\mathrm{m}^{-2} \mathrm{~s}^{-1}$ between 9 and 11 a.m. on a sunny day. Water use efficiency (WUE) was the ratio of leaf $\mathrm{CO}_{2}$ assimilation to transpiration. There were 6 replicates per treatment.

Chl a fluorescence (OJIP) transients were measured after the seedlings were dark-adapted for $3 \mathrm{~h}$ at room temperature with a Handy PEA (Hansatech Instruments Limited, Norfolk, UK) as described by Jiang et al. [52]. OJIP transient was analyzed according to JIP test. Specific energy fluxes per reaction center ( $\mathrm{RC}$ ) for energy 
dissipation $\left(\mathrm{DI}_{\mathrm{o}} / \mathrm{RC}\right)$, maximum photosystem II (PSII) efficiency of dark-adapted leaves $\left(\mathrm{F}_{\mathrm{v}} / \mathrm{F}_{\mathrm{m}}\right)$, quantum yield for energy dissipation $\left(\mathrm{DI}_{\mathrm{o}} / \mathrm{ABS}\right)$, the fraction of oxygen-evolving complexes (OEC) in comparison with control, and total performance index $\left(\mathrm{PI}_{\text {tot,abs }}\right)$ were calculated according to Jiang et al. [52] and Liao et al. [53]. There were 8 replicates per treatment.

\section{Electrolyte leakage, generation rates of $\mathrm{H}_{2} \mathrm{O}_{2}$ and superoxide anion, concentrations of total soluble proteins, MDA, MG and antioxidants in leaves and roots} Electrolyte leakage was measured as described by Long et al. [54]. $\mathrm{H}_{2} \mathrm{O}_{2}$ and superoxide anion generationrates were determined as described previously [55]. Total soluble proteins were measured according to Bradford [56]. MDA was determined spectrophotometrically after being extracted with $80 \%(\mathrm{v} / \mathrm{v})$ ethanol [57]. MG was assayed with an $\mathrm{N}$-acetyl-L-Cys assay according to Wild et al. [58] after being extracted by $5 \%(\mathrm{v} / \mathrm{v}) \mathrm{HClO}_{4}$. GSH and GSSG, and ASC and DHA were assayed according to Chen et al. [55] after being extracted with $5 \%(\mathrm{w} / \mathrm{v})$ trichloroacetic acid (TCA) and 6\% (v/v) of $\mathrm{HClO}_{4}$, respectively. There were 8 replicates per treatment except for 4 replicates for root $\mathrm{H}_{2} \mathrm{O}_{2}$ production rate.

\section{Enzyme activities in leaves and roots}

Glutathione peroxidase (GIPX), SOD, APX, MDHAR, DHAR, GR, CAT, GuPX and GST were extracted with $50 \mathrm{mM} \quad \mathrm{KH}_{2} \mathrm{PO}_{4}-\mathrm{KOH} \quad(\mathrm{pH} 7.5)$ containing $0.1 \mathrm{mM}$ EDTA, $0.3 \%(\mathrm{w} / \mathrm{v})$ Triton X-100 and $4 \%(\mathrm{w} / \mathrm{v})$ insoluble polyvinylpolypyrrolidone (PVPP) [18]. SOD and GuPX were assayed according to Giannopolitis and Ries [59] and Chen et al. [60], respectively. CAT, GR, MDHAR, DHAR and APX were determined according to Chen and Cheng [18]. GIPX and GST were assayed according to Guo et al. (20). There were 8 replicates per treatment.

APR, CS, ATPS, SiR, $\gamma$ GT, $\gamma$ GCS, Gly I and Gly II were extracted according to Lappartient and Touraine [61]. Briefly, six 6-mm-diameter frozen leaf discs or $100 \mathrm{mg}$ frozen root apices were ground with a precooled mortar and pestle in $1 \mathrm{~mL}$ ice-cold extraction buffer containing100 mM Tris- $\mathrm{HCl}$ (pH 8.0), $10 \mathrm{mM}$ EDTA, 2 $\mathrm{mM}$ dithiothreitol (DTT) and 4\% (w/v) insoluble PVPP. ATPS and CS activities were measured according to Guo et al. [20] and Warrilow and Hawkesford [62], respectively. APR activity was determined according to Trüper and Rogers [63] with some modification. Briefly, $1 \mathrm{~mL}$ reaction mixture contained $50 \mathrm{mM}$ Tris- $\mathrm{HCl}(\mathrm{pH} 8.0)$, $0.5 \mathrm{mM} \mathrm{K} \mathrm{K}_{3} \mathrm{Fe}(\mathrm{CN})_{6}, 8 \mathrm{mM}$ EDTA, $0.4 \mathrm{mM}$ AMP, $4 \mathrm{mM}$ $\mathrm{Na}_{2} \mathrm{SO}_{3}$ and $100 \mu \mathrm{L}$ extract. SiR were assayed in $1 \mathrm{~mL}$ reaction mixture containing $10 \mathrm{mM}$ Tris- $\mathrm{HCl}(\mathrm{pH} 7.5), 0.1$ $\mathrm{mM}$ EDTA, $0.5 \mathrm{mM} \mathrm{Na} \mathrm{SO}_{3}, 0.2 \mathrm{mM} \mathrm{NADPH}$ and $100 \mu \mathrm{L}$ enzyme extract [64]. $\gamma \mathrm{GT}$ was assayed as described previously [65]. Briefly, $1 \mathrm{~mL}$ reaction mixture contained $100 \mathrm{mM}$ Tris- $\mathrm{HCl}$ (pH 8.0), $20 \mathrm{mM}$ glycylglycine (Gly-Gly), $2.5 \mathrm{mM} \mathrm{L- \gamma -glutamyl-p-nitroanilide} \mathrm{and}$ $100 \mu \mathrm{L}$ enzyme extract. After $10 \mathrm{~min}$ incubation at $25^{\circ} \mathrm{C}$, the reaction was stopped by the addition of $1 \mathrm{~mL}$ of $25 \%$ $(\mathrm{w} / \mathrm{v})$ TCA. The resultant $\mathrm{p}$-nitroaniline $\left(\varepsilon=1.74 \mathrm{mM}^{-1}\right.$ $\mathrm{cm}^{-1}$ ) was measured at $405 \mathrm{~nm}$. $\gamma$ GCS was assayed in 1 $\mathrm{mL}$ reaction buffer containing $100 \mathrm{mM}$ Tris- $\mathrm{HCl}(\mathrm{pH}$ 8.0), $20 \mathrm{mM} \mathrm{MgCl}, 150 \mathrm{mM} \mathrm{KCl}, 2 \mathrm{mM}$ EDTA, $2 \mathrm{mM}$ phosphoenolpyruvate (PEP), $5 \mathrm{mM}$ ATP, $10 \mathrm{mM}$ glutamate, $10 \mathrm{mM} \alpha$-aminobutyrate, $0.2 \mathrm{mM} \mathrm{NADH}, 7 \mathrm{U}$ pyruvate kinase (PK), $10 \mathrm{U}$ lactate dehydrogenase $(\mathrm{LDH})$ and $100 \mu \mathrm{L}$ enzyme extract [65]. Gly I and Gly II activities were assayed as described previously [66]. There were 8 replicates per treatment.

Glutamine synthetase (GS) was extracted and assayed as previously [20]. There were 6 replicates for leaf GS and 4 replicates for root GS per treatment.

\section{Data analysis}

There were 20 pots (40 seedlings) per treatment in a completely randomized design. Results were expressed as mean $\pm \operatorname{SE}(n=4-10)$. Significant differences between Mg-deficient roots and controls were made by unpaired $t$-test. Four means [two (Mg levels) $\times$ two (leaf positions)] were analyzed by two ANOVA followed by Duncan's new multiple range test.

Principal component analysis (PCA) and Pearson correlation analysis for all the measured parameters except for leaf gas exchange and Chl a fluorescence parameters were performed using a $\mathrm{SPSS}^{\circ}$ statistical software (version 17.0, IBM, NY, USA), as described previously [20,37].

\section{Results}

Typical Mg-deficient symptoms occurred only in Mgdeficient lower leaves, and Mg-deficiency affected $\mathbf{M g}$ concentration more in leaves than in roots

In addition to inhibiting seedling growth, $0 \mathrm{mM} \mathrm{Mg-treat-}$ ment led to a typical Mg-deficient system (leaf chlorosis) in the basal older leaves. The symptom first occurred in the old leaves, and then extended gradually to the young leaves with the prolongation of Mg-deficiency duration (Additional file 1: Fig. S1). Similar to Citrus boron (B)-deficiency $[3,67]$, enlargement and corkiness of midrib and main lateral veins were observed in $0 \mathrm{mM} \mathrm{Mg}$-treated old (lower) leaves, but not in the upper leaves. Seedlings supplied with $2 \mathrm{mMMg}$ did not display any Mg-deficient symptoms (Additional file 1: Figure S1). Also, foliar Mg level (Fig. 1a) fell in the normal range [43]. Therefore, plants exposed to $2 \mathrm{mM}$ and $0 \mathrm{mM} \mathrm{Mg}$ are considered as $\mathrm{Mg}$-sufficient (control) and $\mathrm{Mg}$-deficient, respectively.

Mg-deficiency-induced decrease in Mg concentration was in the order of lower leaves > upper leaves $>$ roots. The lower leaves had less Mg concentration than the 

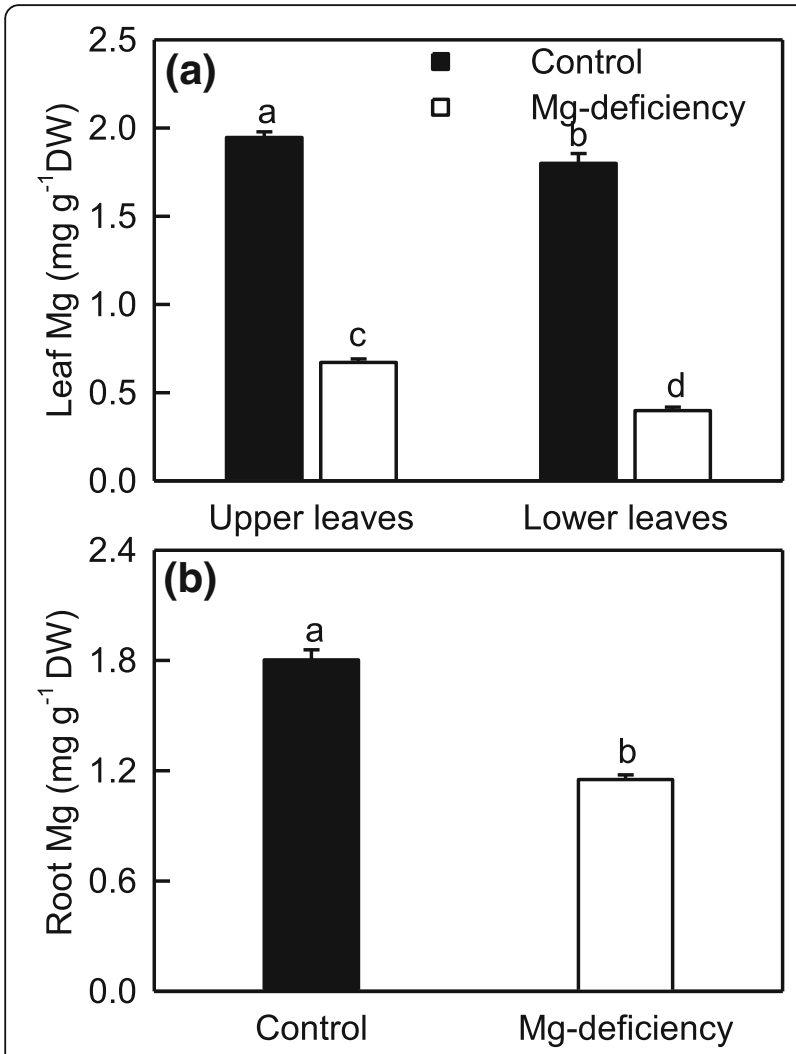

Fig. $1 \mathrm{Mg}$-deficient effects on the concentration of $\mathrm{Mg}$ in C. sinensis leaves (a) and roots (b). Bars represent means \pm SE $(n=10)$. Significant differences between $\mathrm{Mg}$-deficient roots and controls were made by unpaired $t$-test. Four means [two (Mg levels) $\times$ two (leaf positions)] were analyzed by two ANOVA followed by Duncan's new multiple range test. Different letters above the bars indicate a significant difference at $P<0.05$

upper leaves under the same concentration of Mg supply (Fig. 1).

Gas exchange and $\mathrm{Chl}$ a fluorescence parameters were greatly altered in the Mg-deficient lower leaves, but not in the Mg-deficient upper leaves with the exception of a few

As shown in Fig. 2, the Mg-deficient lower leaves had decreased $\mathrm{CO}_{2}$ assimilation, stomatal conductance $\left(\mathrm{g}_{\mathrm{s}}\right)$, transpiration, WUE, $F_{v} / F_{m}$, the fraction of OEC in comparison with control and $\mathrm{PI}_{\text {tot,abs }}$, but increased ratio of intercellular to ambient $\mathrm{CO}_{2}$ concentration $\left(\mathrm{C}_{\mathrm{i}} / \mathrm{C}_{\mathrm{a}}\right), \mathrm{DI}_{\mathrm{o}} /$ $\mathrm{RC}$ and $\mathrm{DI}_{\mathrm{o}} / \mathrm{ABS}$ in the lower leaves. However, only $\mathrm{CO}_{2}$ assimilation, $g_{s}$ and $\mathrm{PI}_{\text {totabs }}$ were significantly decreased in the Mg-deficient upper leaves. Thus, it is reasonable to assume that the Mg-deficiency-induced alterations of leaf gas exchange and fluorescence parameters increased with increasing ages. Under Mg-deficiency, the upper leaves had higher $\mathrm{CO}_{2}$ assimilation, $\mathrm{g}_{\mathrm{s}}$, transpiration, WUE, $F_{v} / F_{m}$, the fraction of OEC in comparison with control and $\mathrm{PI}_{\text {tot,abs }}$ than the lower leaves, but lower $\mathrm{C}_{\mathrm{i}} /$
$\mathrm{C}_{\mathrm{a}}, \mathrm{DI}_{\mathrm{o}} / \mathrm{RC}$ and $\mathrm{DI}_{\mathrm{o}} / \mathrm{ABS}$. Under Mg-sufficiency, all the ten parameters were similar between the upper and lower leaves except that $\mathrm{CO}_{2}$ assimilation was slightly higher in the upper leaves than that in the lower leaves. Obviously, Mg-deficiency increased greatly the differences in gas exchange and fluorescence parameters between the upper and lower leaves.

Electrolyte leakage, superoxide anion and $\mathrm{H}_{2} \mathrm{O}_{2}$ generation rates, and MDA and MG levels were greatly increased in the Mg-deficient lower leaves and roots, but not in the Mg-deficient upper leaves

Since $\mathrm{CO}_{2}$ assimilation was greatly inhibited in the Mg-deficient lower leaves, but only slightly inhibited in the Mg-deficient upper leaves (Fig. 2a), the fraction of the absorbed light allocated to photosynthetic electron transport might be greatly decreased only in the $\mathrm{Mg}$-deficient lower leaves. As a result, more excess light energy might exist in the Mg-deficient lower leaves, as indicated by the increased $\mathrm{DI}_{\mathrm{o}} / \mathrm{ABS}$ and $\mathrm{DI}_{\mathrm{o}} / \mathrm{RC}$, but not in the Mg-deficient upper leaves, as indicated by the unaltered $\mathrm{DI}_{\mathrm{o}} / \mathrm{ABS}$ and $\mathrm{DI}_{\mathrm{o}} / \mathrm{RC}$ (Fig. 2f-h). The excess absorbed light energy can potentially promote the production of ROS and MG, thus impairing redox homeostasis and causing lipid peroxidation [18, 20]. Lipid peroxidation may lead to the loss of membrane integrity and the increase of electrolyte leakage [19, 20, 34, 35]. For this purpose, we investigated the Mg-deficient effects on electrolyte leakage, superoxide anion and $\mathrm{H}_{2} \mathrm{O}_{2}$ generation rates, and MDA and MG levels in the upper and lower leaves. All the five parameters were greatly increased in the Mg-deficient lower leaves, but not in the Mg-deficient upper leaves except for a slight increase in $\mathrm{H}_{2} \mathrm{O}_{2}$ production rate. Thus, all the five parameters did not significantly differ between the upper and lower leaves except for a slightly higher $\mathrm{H}_{2} \mathrm{O}_{2}$ production rate in the lower leaves under Mg-sufficiency, but they were higher in the lower leaves than those in the upper leaves under Mg-deficiency (Fig. 3a-e). Like to the lower leaves, all the five parameters were greatly elevated in the Mg-deficient roots (Fig. 3f-j).

\section{Relationships between $\mathrm{CO}_{2}$ assimilation, $\mathrm{Chl}$ a fluorescence parameters, electrolyte leakage, ROS production rates, MDA and MG levels in leaves}

We calculated the linear correlation coefficients between $\mathrm{CO}_{2}$ assimilation, $\mathrm{F}_{\mathrm{v}} / \mathrm{F}_{\mathrm{m}}, \mathrm{DI}_{\mathrm{o}} / \mathrm{RC}, \mathrm{DI}_{\mathrm{o}} / \mathrm{ABS}$, the fraction of OEC in comparison with control, $\mathrm{PI}_{\text {totabs }}$, electrolyte leakage, ROS production rates, MDA and MG levels in leaves in order to understand the relationships between them (Table 1). Most of these physiological parameters were positively or negatively related with each other. Indeed, only ten correlation coefficients (a total of 55) were not significant. 


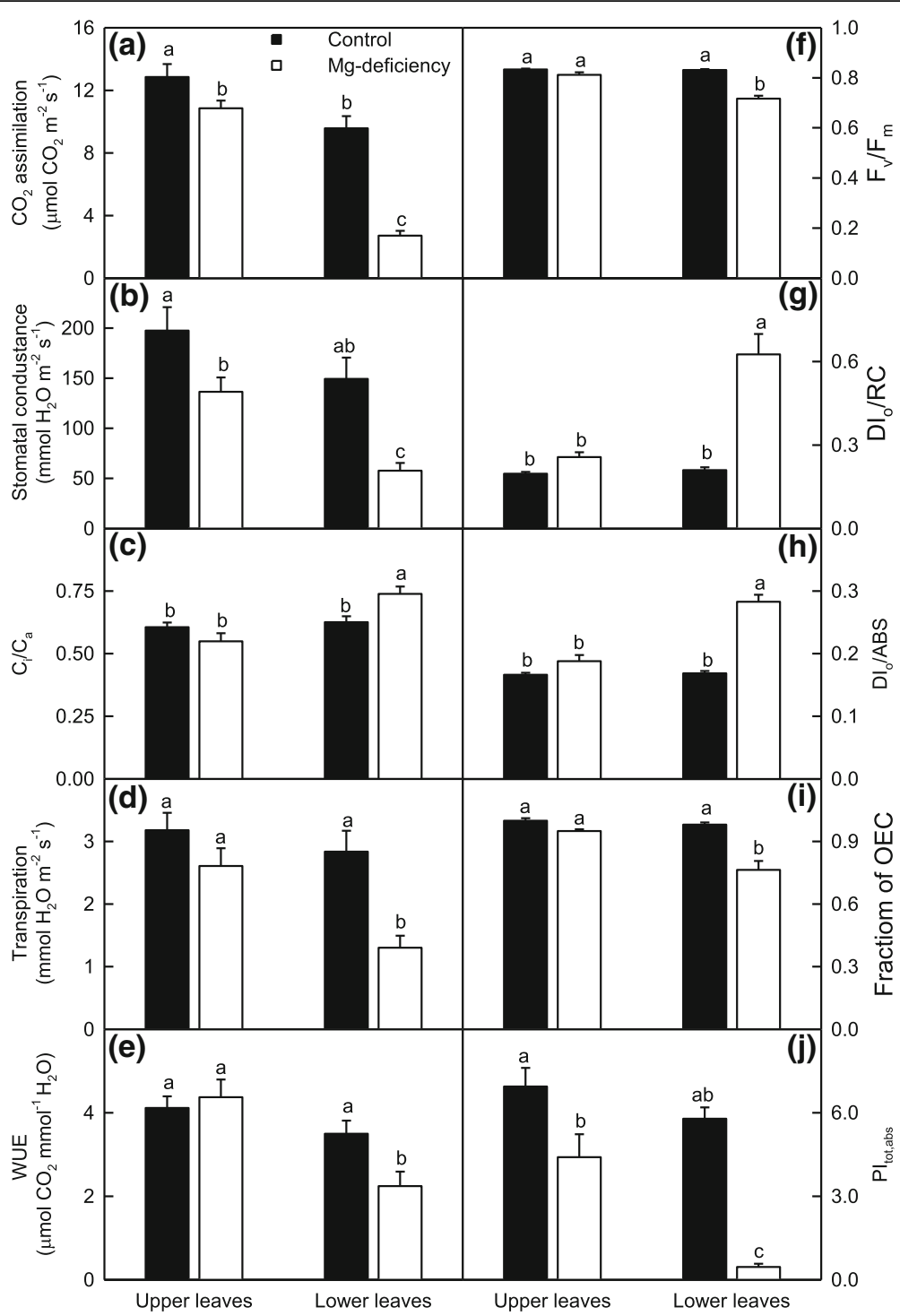

Fig. $2 \mathrm{Mg}$-deficient effects on $\mathrm{CO}_{2}$ assimilation $(\mathbf{a})$, stomatal conductance $\left(\mathrm{g}_{\mathrm{s}} \mathbf{b}\right)$, the ratio of intercellular to ambient $\mathrm{CO}_{2}$ concentration $\left(\mathrm{C}_{\mathrm{i}} / \mathrm{C}_{\mathrm{a}}\right.$; $\mathbf{c}$ ), transpiration $(\mathbf{d})$, water use efficiency $(W U E, \mathbf{e}), \mathrm{F}_{\mathrm{v}} / \mathrm{F}_{\mathrm{m}}(\mathbf{f}), \mathrm{DI} / \mathrm{RC}(\mathbf{g}), \mathrm{DI} / \mathrm{ABS}(\mathbf{h})$, the fraction of OEC in comparison with control (i) and $\mathrm{Pl}$ totabs $(\mathbf{j})$ in $C$. sinensis leaves. Bars represent means \pm SE ( $n=6$ for gas exchange or 8 for fluorescence parameters). Significant differences between Mg-deficient roots and controls were made by unpaired $t$-test. Four means [two (Mg levels) $\times$ two (leaf positions)] were analyzed by two ANOVA followed by Duncan's new multiple range test. Different letters above the bars indicate a significant difference at $P<0.05$

\section{Mg-deficiency-induced changes in the activities of} enzymes involved in ROS and MG detoxification were more pronounced in the lower leaves and roots than in the upper leaves

To deal with oxidative injury, plants have evolved efficient enzymatic and non-enzymatic scavenging systems. Antioxidant enzymes are the first line of defense against the oxidative injury [21]. As shown in Fig. 4, Mg-deficiency increased the activities of APX, MDHAR, DHAR, SOD and GuPX in the roots and lower leaves whether the data were expressed on a DW or protein basis, but had less influence on them in the upper leaves. By contrast, CAT activity was reduced in the
Mg-deficient leaves and roots. Under Mg-deficiency, the activities of APX, MDHAR, DHAR, SOD and GuPX were higher in the lower leaves than those in the upper leaves, whereas the activity of CAT was higher in the upper leaves than that in the lower leaves or similar between the two depending on how the data were expressed. Under Mg-sufficiency, the activities of all the six antioxidant enzymes were similar between the upper and lower leaves except that SOD activity (APX activity on a DW basis) was slightly higher (less) in the lower leaves than that in the upper leaves.

Thiol-based antioxidant system is the second line of defense against the oxidative injury [21]. In the lower 

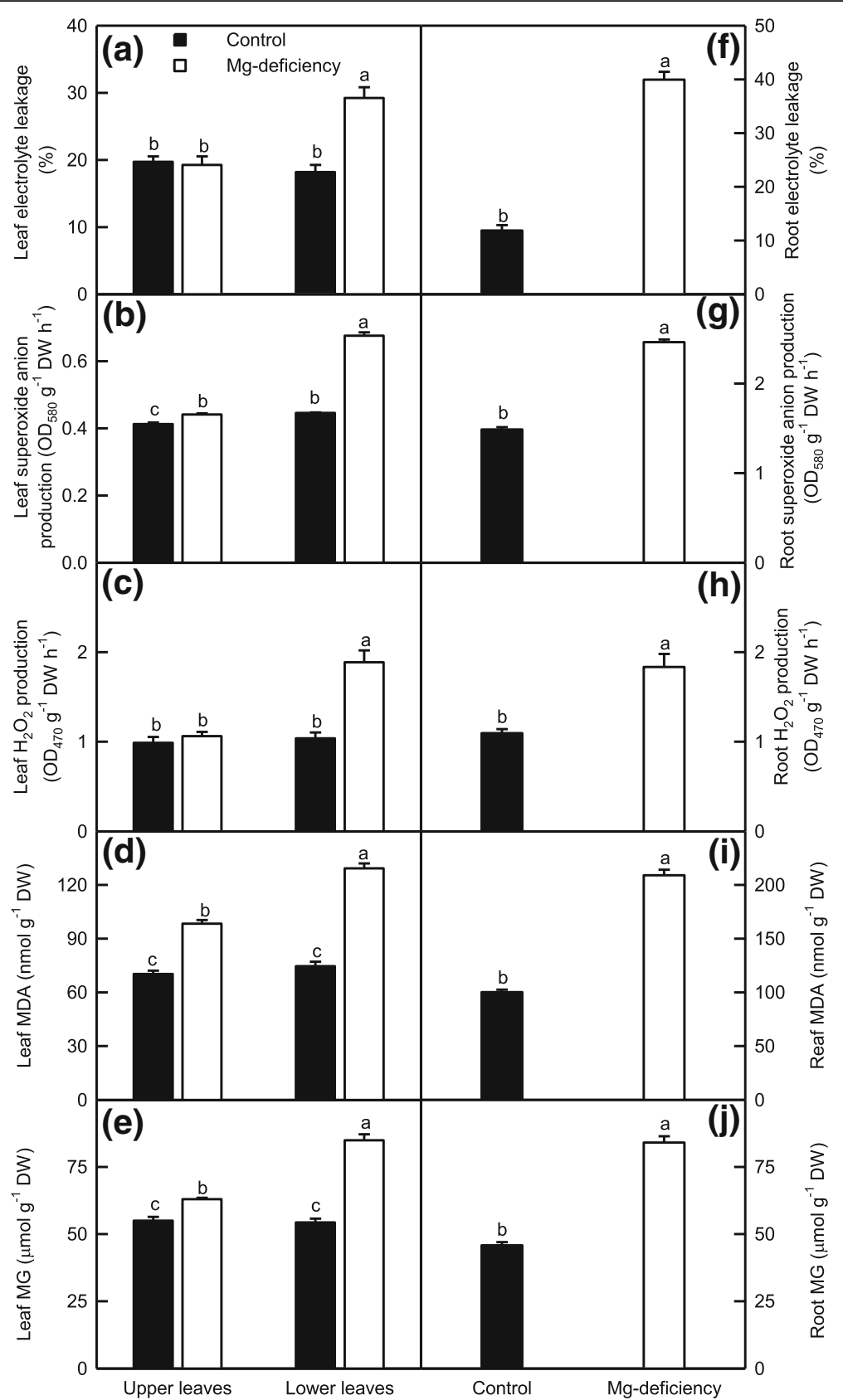

Fig. 3 Mg-deficient effects on electrolyte leakage $\left(\mathbf{a}\right.$, $\mathbf{f}$ ), superoxide anion $(\mathbf{b}, \mathbf{g})$ and $\mathrm{H}_{2} \mathrm{O}_{2}(\mathbf{c}, \mathbf{h})$ production rates, $\mathrm{MDA}(\mathbf{d}$, $\mathbf{i})$ and $\mathrm{MG}(\mathbf{e}$, $\mathbf{j})$ concentrations in $\mathrm{C}$. sinensis leaves (a-e) and roots (f-j). Bars represent means $\pm \mathrm{SE}\left(n=8\right.$ except for 4 for root $\mathrm{H}_{2} \mathrm{O}_{2}$ production rate). Significant differences between $\mathrm{Mg}$-deficient roots and controls were made by unpaired $t$-test. Four means [two (Mg levels) $\times$ two (leaf positions)] were analyzed by two ANOVA followed by Duncan's new multiple range test. Different letters above the bars indicate a significant difference at $P<0.05$

leaves, Mg-deficiency decreased the activities of GST, APR and CS on a DW or protein basis and of $\gamma \mathrm{GT}$ and GS on a DW basis, increased the activities of GR, ATPS, GIPX, $\gamma$ GCS and SiR on a DW or protein basis and of $\gamma \mathrm{GT}$ on a protein basis, and did not affect the activity of GS on a protein basis. In the upper leaves, Mg-deficiency did not affect the activities of all the ten enzymes related to $\mathrm{S}$ metabolism except that Mg-deficiency slightly increased the activity of ATPS, and slightly decreased the activities of APR on a DW or protein basis and of $\gamma$ GT and GS on a DW basis. Under Mg-deficiency, the activities of GST, APR, CS on a DW or protein basis and of $\gamma \mathrm{GT}$ and GS on a DW basis were higher in the upper leaves than those in the lower leaves, whereas the reverse was the case for the activities of GR, ATPS, 
Table 1 Pearson correlation coefficient matrix for 11 physiological parameters in C. sinensis leaves. Data are from Figs. 2 and 3 ; *,** and ${ }^{* *}$ indicate a significant difference at $P<0.05, P<0.01$ and $P<0.001$, respectively. $\mathrm{A}: \mathrm{CO}_{2}$ assimilation; FoEc: The fraction of OEC in comparison with control; EL: Electrolyte leakage; SAP: Superoxide anion production rate; $\mathrm{HP}: \mathrm{H}_{2} \mathrm{O}_{2}$ production rate

\begin{tabular}{|c|c|c|c|c|c|c|c|c|c|c|c|}
\hline & A & $F_{\mathrm{v}} / F_{m}$ & $\mathrm{DI}_{0} / \mathrm{RC}$ & $\mathrm{DI}_{\mathrm{O}} / \mathrm{ABS}$ & $\mathrm{F}_{\mathrm{OEC}}$ & $P l_{\text {tot,abs }}$ & $\mathrm{EL}$ & SAP & $\mathrm{HP}$ & MDA & $M G$ \\
\hline $\bar{A}$ & 1 & & & & & & & & & & \\
\hline$F_{\mathrm{v}} / F_{\mathrm{m}}$ & 0.9492 & 1 & & & & & & & & & \\
\hline $\mathrm{DI}_{0} / \mathrm{RC}$ & $-0.9569^{*}$ & $-0.9987^{* *}$ & 1 & & & & & & & & \\
\hline $\mathrm{DI}_{\mathrm{O}} / \mathrm{ABS}$ & -0.9489 & $-1.0000^{* * *}$ & $0.9986^{* *}$ & 1 & & & & & & & \\
\hline$F_{O E C}$ & $0.9629^{*}$ & $0.9986^{* *}$ & $-0.9976^{* *}$ & $-0.9985^{* *}$ & 1 & & & & & & \\
\hline $\mathrm{Pl}_{\text {tot,abs }}$ & 0.9484 & $0.9754^{*}$ & $-0.9673^{*}$ & $-0.9755^{*}$ & $0.9823^{*}$ & 1 & & & & & \\
\hline EL & -0.9080 & $-0.9798^{*}$ & $0.9845^{*}$ & $0.9797^{*}$ & $-0.9706^{*}$ & -0.9116 & 1 & & & & \\
\hline SAP & $-0.9806^{*}$ & $-0.9876^{*}$ & $0.9934^{* *}$ & $0.9874^{*}$ & $-0.9910^{* *}$ & $-0.9573^{*}$ & $0.9723^{*}$ & 1 & & & \\
\hline $\mathrm{HP}$ & $-0.9656^{*}$ & $-0.9924^{* *}$ & $0.9974^{* *}$ & $0.9922^{* *}$ & $-0.9922^{* *}$ & $-0.9529^{*}$ & $0.9854^{*}$ & $0.9978^{* *}$ & 1 & & \\
\hline MDA & -0.8838 & $-0.9550^{*}$ & 0.9395 & $0.9553^{*}$ & $-0.9569^{*}$ & $-0.9863^{*}$ & 0.8869 & 0.9114 & 0.9141 & 1 & \\
\hline MG & -0.9202 & $-0.9941^{* *}$ & $0.9873^{*}$ & $0.9942^{* *}$ & $-0.9910^{* *}$ & $-0.9809^{*}$ & $0.9643^{*}$ & $0.9655^{*}$ & $0.9731^{*}$ & $0.9776^{*}$ & 1 \\
\hline
\end{tabular}

GIPX, $\gamma$ GCS and SiR on a DW or protein basis and of $\gamma \mathrm{GT}$ and GS on a protein basis. Under Mg-sufficiency, the activities of all the ten $\mathrm{S}$ metabolism-related enzymes did not significantly differ between the lower and upper leaves with the exceptions that the activities of ATPS on a DW or protein basis and of GST and $\gamma \mathrm{GT}$ on a protein basis were slightly higher in the lower leaves than those in the upper leaves, and that the activities of APR and

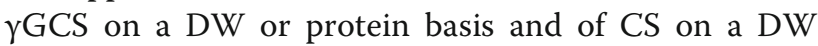
basis were slightly higher in the upper leaves than those in the lower leaves. In the roots, Mg-deficiency increased the activities of GST, GR, ATPS, GIPX and $\gamma \mathrm{GCS}$, and decreased the activities of the other five enzymes, regardless of how the data were expressed (Figs. 5-6).

Both Gly I and Gly II play a key role in the detoxification of MG [35]. As shown in Fig. 7, Mg-deficiency led to a decreased activity of Gly I and an increased activity of Gly II in the lower leaves and roots whether the data were expressed on a DW or protein basis, but did not affect their activities in the upper leaves except that Mg-deficiency slightly decreased the activity of Gly I on a DW basis. Under Mg-deficiency, the activity of Gly I was higher in the upper leaves than that in the lower leaves, whereas the reverse was the case for the activity of Gly II. Under Mg-sufficiency, the activities of Gly I and Gly II were similar between the upper and lower leaves.

To conclude, Mg-deficiency altered greatly the activities of enzymes involved in ROS and MG detoxification in the lower leaves and roots, but not in the upper leaves with a few of exceptions. The activities of these enzymes differed greatly between the Mg-deficient lower and upper leaves, but not between the $\mathrm{Mg}$-sufficient lower and upper leaves.
Mg-deficiency-induced alterations of antioxidants were greater in the Mg-deficient lower leaves and roots than in the Mg-deficient upper leaves

We assayed the concentrations of GSH, GSSG, ASC and DHA, the important small molecular substances involved in the detoxification of ROS and MG, in the leaves and roots (Fig. 8). Mg-deficiency increased GSSG concentration, decreased GSH concentration and GSH/ $(\mathrm{GSH}+\mathrm{GSSG})$ ratio in the leaves and roots, with a greater change in the lower leaves and roots than in the upper leaves. However, GSH + GSSG concentration was not significantly altered in the Mg-deficient leaves and roots. Compared with the Mg-deficient upper leaves, the Mg-deficient lower leaves had higher concentration of GSSG and lower ratio of GSH/(GSH + GSSG), but similar concentrations of GSH + GSSG and GSH. Under Mg-sufficiency, all the four parameters were similar between the lower and upper leaves (Fig. 8a-d and i-l).

As shown in Fig. 8e-h and $\mathrm{m}-\mathrm{p}$, the concentrations of ASC + DHA, ASC and DHA were greatly increased and decreased in the $\mathrm{Mg}$-deficient lower leaves and roots, respectively, while the ratio of $\mathrm{ASC} /(\mathrm{ASC}+\mathrm{DHA})$ was slightly decreased in the $\mathrm{Mg}$-deficient lower leaves and roots. All the four parameters kept unchanged in the Mg-deficient upper leaves. Under Mg-deficiency, the lower leaves had higher concentrations of ASC + DHA, ASC and DHA and lower ratio of $\mathrm{ASC} /(\mathrm{ASC}+\mathrm{DHA})$ relative to the upper leaves. Under $\mathrm{Mg}$-sufficiency, all the four parameters did not significantly differ between the two.

In conclusions, Mg-deficiency affected antioxidants more in the lower leaves and roots than those in the upper leaves. The concentrations of antioxidants and the ratios of $\mathrm{GSH} /(\mathrm{GSH}+\mathrm{GSSG})$ and $\mathrm{ACS} /(\mathrm{ASC}+\mathrm{DHA})$ were significantly different between the $\mathrm{Mg}$-deficient lower and upper leaves except for GSH and GSH + 


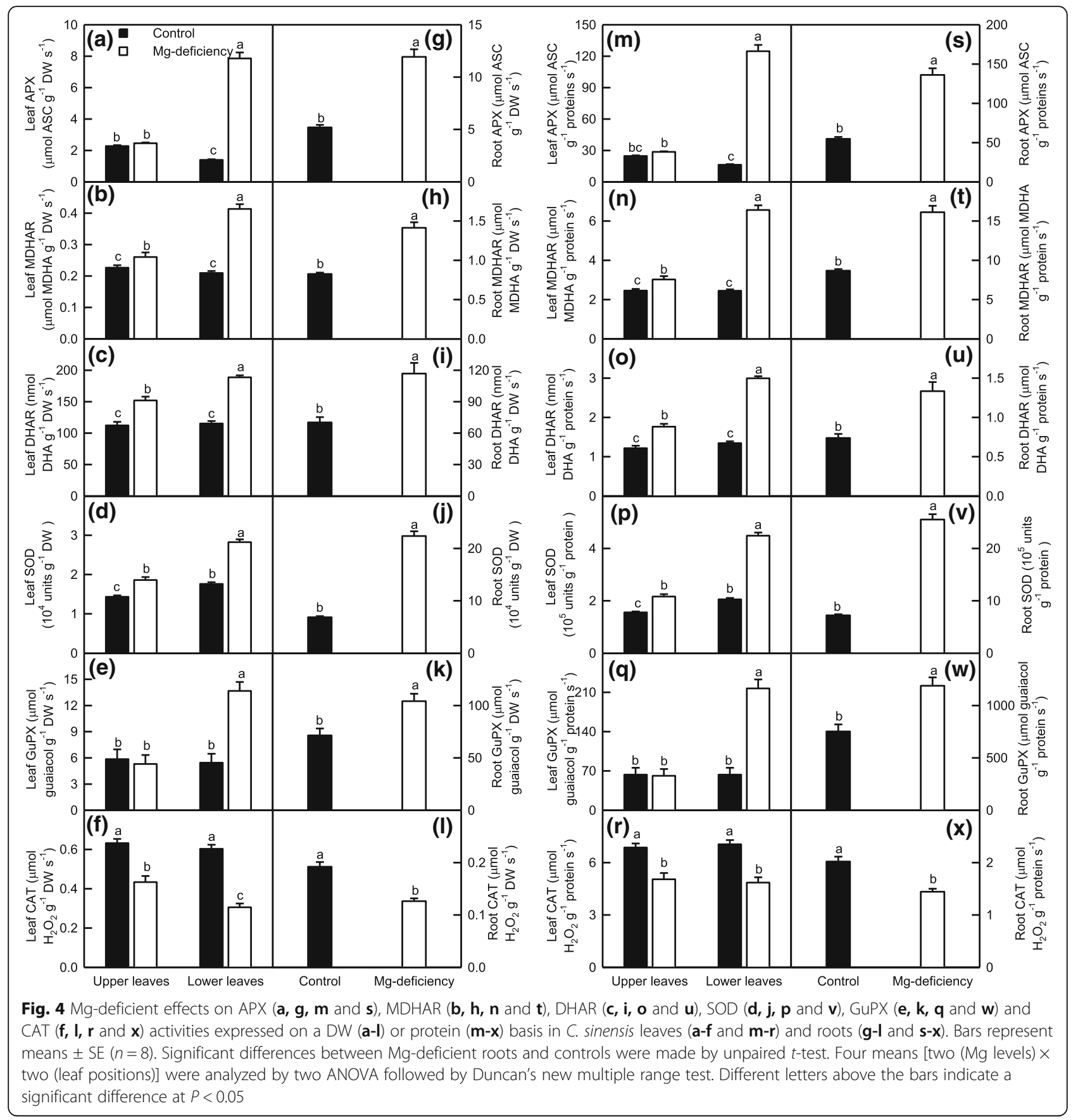

GSSG concentrations, but they were similar between the Mg-sufficient lower and upper leaves.

\section{MG in relation to GSH, Gly I and Gly II in leaves}

Here, we calculated the linear correlation coefficients between MG concentration and GSH concentration, Gly I or Gly II activity in order to investigate their roles in the detoxification of MG (Fig. 9). Leaf MG concentration displayed a significant and linear decrease with increasing Gly I activity on a DW basis and a decreased trend with increasing GSH concentration and Gly I activity on a protein basis. However, leaf MG concentration increased linearly and significantly with increasing Gly II activity, regardless of how the data were expressed.

\section{PCA loading plots and correlation}

Through PCA, we revealed the differences in the response patterns of ROS and MG metabolisms to Mg-deficiency among the upper and lower leaves and roots (Fig. 10; Additional files 1: Tables S1, S2, S3). In the lower leaves and 


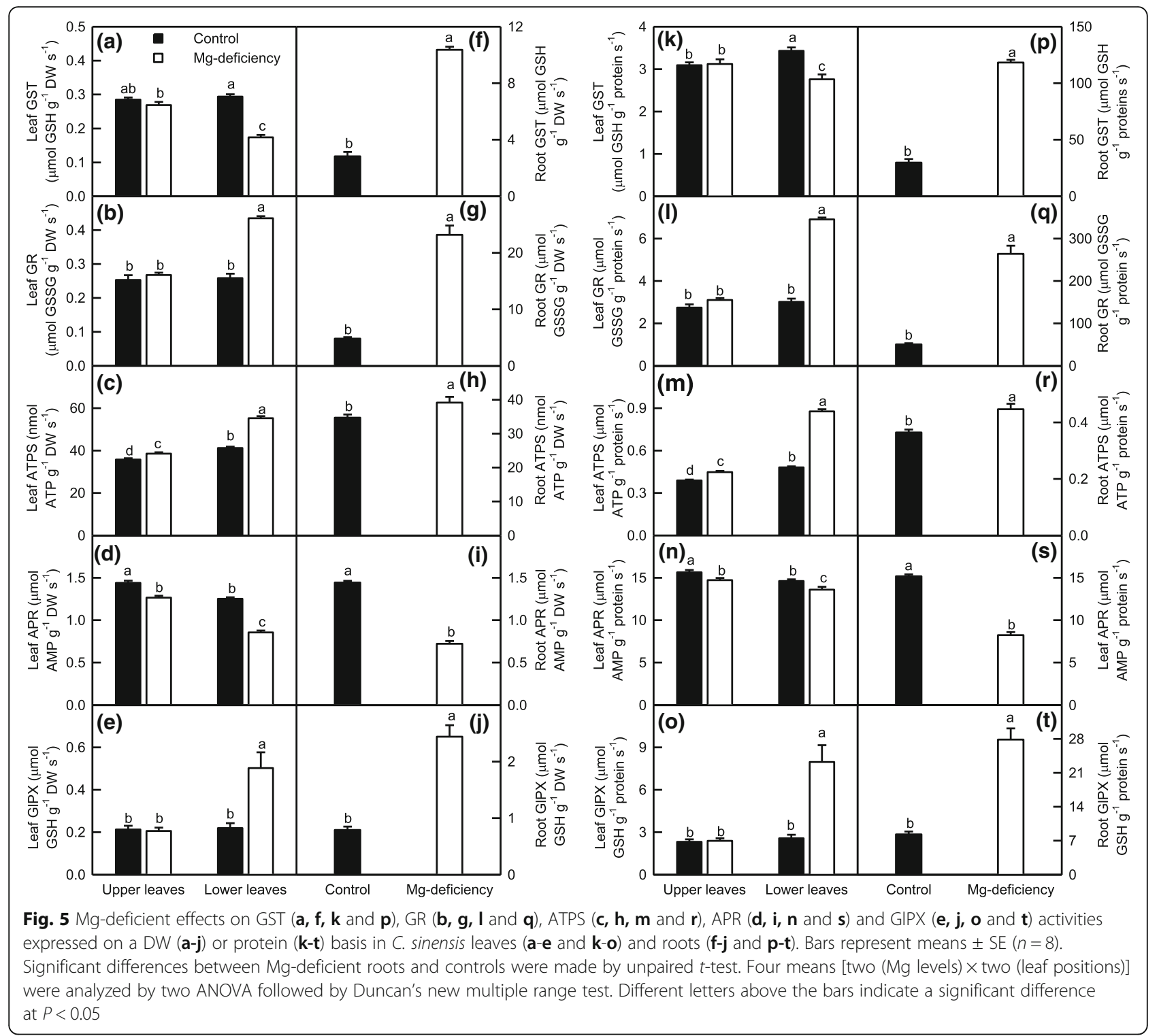

roots, most of ROS and MG metabolism-related parameters were highly clustered into left and right two groups. However, no obvious clustered parameters were observed in the upper leaves. The first two components comprised $88.9 \%$ (81.6\% for PC1 and 7.3\% for PC2) and 89.9\% (82.1\% for PC1 and $7.8 \%$ for $\mathrm{PC} 2$ ) of the total variation in the lower leaves and roots, respectively, but only $56.2 \%$ (PC1 for $35.8 \%$ and PC2 for 20.4\%) in the upper leaves. Evidently, the Mg-deficient effects on these parameters were far less in the upper leaves and roots than those in the lower leaves. For the upper leaves, MDA (0.9766), Mg (-0.9764), MG (0.8772), APR-D (-D: enzyme activity expressed on a DW basis; - 0.8695), APX-P (-P: enzyme activity expressed on a protein basis; 0.8692), DHAR-P (0.8362), SOD-P (0.8216) and ASC + DHA (0.8140) were the most influential in the PC1. For the lower leaves, the PC1 was loaded largely on
CS-D (- 0.9960), DHA (0.9897), CS-P (- 0.9883), Gly II-P (0.9837), $\gamma$ GT-D (-0.9831), DHAR-P (0.9820), $\gamma$ GCS-P $(0.9815)$ and Gly I-D (-0.9806). For the roots, PC1 was the mostly influenced by the alterations of MDA (0.9966), GST-P (0.9938), GST-D (0.9936), $\gamma$ GCS-P (0.9871), ASC ($0.9858)$, ASC + DHA (- 0.9857), $\gamma$ GCS-D (0.9853) and electrolyte leakage $(0.9849)$. It is worth noting that the Mg-deficiency-induced separation of these parameters also differed between the lower leaves and roots. For the lower leaves, seven parameters of antioxidants lay in the 1st and 2nd quadrants, only one parameter lay in the 4th quadrant; for the roots, three parameters of antioxidants lay in the 1st and 2nd quadrants, and five parameters lay in the 3rd and 4th quadrants.

Pearson correlation analysis was made using all the parameters for PCA in order to understand the relationships 


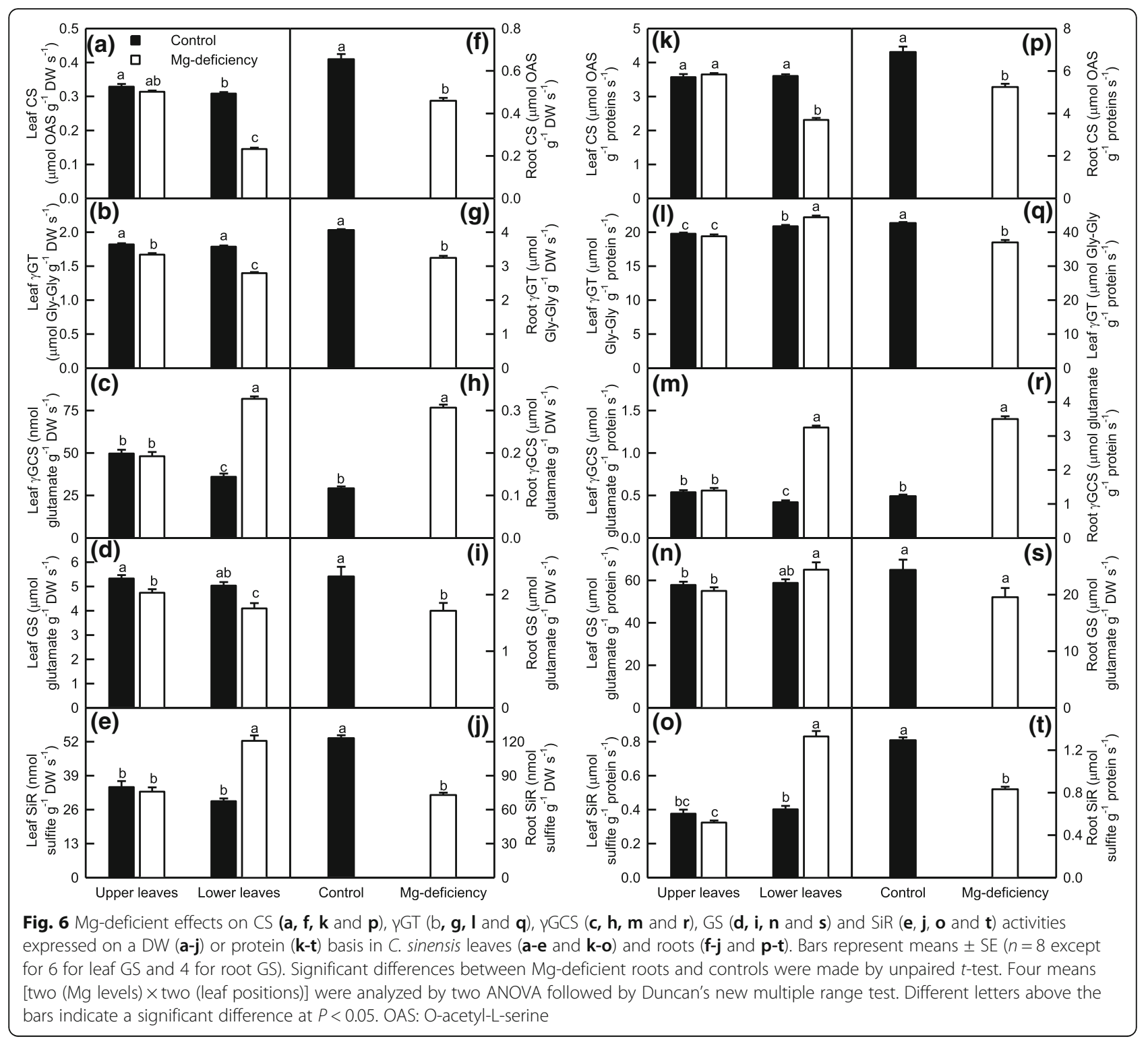

between these parameters (Fig. 11). Majority of these parameters were positively or negatively related with each other in the lower leaves and roots, but did not display any clear relationships in the upper leaves. Compared with the roots, more positive and less negative relationships between the parameters existed in the lower leaves.

\section{Discussion}

Responses of ROS and MG metabolisms to Mg-deficiency were far greater in the lower leaves and roots than those in the upper leaves, and Mg-deficiency enhanced greatly their differences between the lower and upper leaves

Based on our findings and the available data in the literatures, a scheme displayed the $\mathrm{Mg}$-deficient effects on gas exchange, Chl a fluorescence, $\mathrm{Mg}$, and ROS and MG metabolisms in the leaves and roots was presented here
(Fig. 12). Under Mg-deficiency, all these parameters (60 parameters in the leaves and 50 parameters in the roots) were significantly altered in the lower leaves and roots except for GSH + GSSG concentration, but only 25 parameters were significantly altered in the upper leaves. Moreover, the Mg-deficiency-induced alterations of the 25 (22 parameters in roots) parameters were far less in the upper leaves than those in the lower leaves (roots) (Figs. 1-8). The only exception was that the $\mathrm{Mg}$-deficiency-induced decrease in $\mathrm{Mg}$ level was greater in the upper leaves than that in the roots. Obviously, the responses of all these parameters to $\mathrm{Mg}$-deficiency were far more pronounced in the lower leaves and roots than those in the upper leaves. It is worth mentioning that many (35) of parameters were not significantly affected in the Mg-deficient upper leaves. This may be related to 

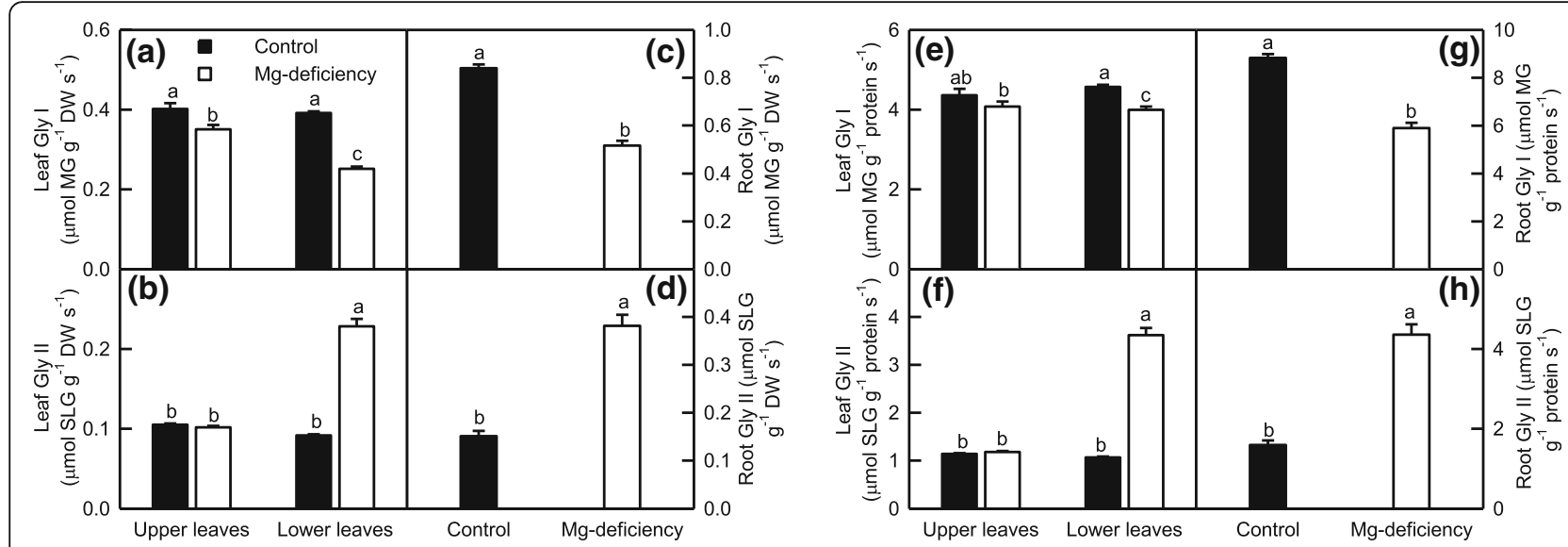

Fig. $7 \mathrm{Mg}$-deficient effects on Gly I ( $\mathbf{a}, \mathbf{c}, \mathbf{e}$ and $\mathbf{g})$ and Gly II (b, $\mathbf{d}, \mathbf{f}$ and $\mathbf{h}$ ) activities expressed on a DW (a-d) or protein (e-h) basis in C. sinensis leaves (a-b and $\mathbf{e}-\mathbf{f})$ and roots $(\mathbf{c}-\mathbf{d}$ and $\mathbf{g}-\mathbf{h})$. Bars represent means \pm SE $(n=8)$. Significant differences between Mg-deficient roots and controls were made by unpaired $t$-test. Four means [two (Mg levels) $\times$ two (leaf positions)] were analyzed by two ANOVA followed by Duncan's new multiple range test. Different letters above the bars indicate a significant difference at $P<0.05$

the fact that the transport of $\mathrm{Mg}$ from older leaves to the younger leaves is improved under Mg-deficient conditions, thus providing $\mathrm{Mg}$ for the normal growth and development of the young leaves $[38,68]$, since Mg-deficiency-induced decrease was significantly less in the upper leaves than that in the lower leaves (Fig. 1a). This is also supported by our observation that the typical symptom of Mg-deficiency occurred only in the Mg-deficient lower leaves (Additional file 1: Fig. S1). In a study with C. sinensis, Li et al. [3] reported that many of physiological parameters (namely gas exchange, the concentrations of pigments, OA, total soluble proteins, amino acids and phenolics, and the activities of key enzymes involved in OA, amino acid and phenolic metabolisms) were significantly affected in the $\mathrm{Mg}$-deficient lower leaves, but not in the Mg-deficient upper leaves. As shown in Fig. 10, all these parameters for PCA were highly clustered into the left and right two groups in the lower leaves and roots, but not in the upper leaves. The majority of parameters for PCA were positively or negatively related with each other only in the lower leaves and roots, but not in the upper leaves (Fig. 11). Obviously, the responses of ROS and MG metabolisms to Mg-deficiency occurred highly only in the lower leaves and roots rather than in the upper leaves. In a word, the Mg-deficient effects on ROS and MG metabolisms were far greater in the lower leaves and roots than those in the upper leaves.

As shown in Figs. 3-8, many of ROS and MG metabolism-related parameters differed significantly only between the Mg-deficient lower and upper leaves, but not between the Mg-sufficient lower and upper leaves. Although leaf positions had influence on some of parameters under Mg-sufficiency, the influence was far less than under Mg-deficiency. Evidently, the differences in
ROS and MG metabolisms between the lower and upper leaves were greatly elevated by $\mathrm{Mg}$-deficiency.

\section{ROS detoxification systems as a whole did not provide considerable protect from oxidative damage in the Mg- deficient leaves and roots}

Nutrient deficiencies can break the balance between the production of ROS and their removal via detoxification systems, thus causing ROS over-accumulation and lipid peroxidation in root and leaf cells $[1,2,16,24,69,70]$. Here, the production rates of superoxide anion and $\mathrm{H}_{2} \mathrm{O}_{2}$ and the concentration of MDA were increased in the Mg-deficient leaves and roots, with a greater increase in the Mg-deficient lower leaves and roots than those in the upper leaves except for leaf $\mathrm{H}_{2} \mathrm{O}_{2}$ generation rate (Fig. 3b-d and g-i). Regressive analysis showed that leaf superoxide anion or $\mathrm{H}_{2} \mathrm{O}_{2}$ production rate increased linearly with increasing $\mathrm{DI}_{\mathrm{o}} / \mathrm{RC}$ or $\mathrm{DI}_{\mathrm{o}} / \mathrm{ABS}$, and decreased linearly with increasing $\mathrm{CO}_{2}$ assimilation, $\mathrm{F}_{\mathrm{v}} /$ $\mathrm{F}_{\mathrm{m}}$, the fraction of OEC in comparison with control or $\mathrm{PI}_{\text {tot,abs }}$ (Table 1). Thus, the greater increases in the ROS production rates in the Mg-deficient lower leaves might be caused by more excess absorbed light energy due to decreased photosynthetic electron transport resulting from a larger decrease in $\mathrm{CO}_{2}$ assimilation. It is worth noting that leaf MDA concentration increased linearly with increasing MG concentration, but only displayed an upward trend with increasing superoxide anion or $\mathrm{H}_{2} \mathrm{O}_{2}$ production rate (Table 1). Over-accumulation of $\mathrm{MG}$ can also lead to lipid peroxidation in plant cells $[35,36]$. Yadav et al. [36] reported that the salt-induced increases of MG and MDA concentrations in the leaves were much less in Gly I and/or Gly II overexpressing transgenic tobacco plants than those in wild-type (WT) plants. Thus, it is reasonable to assume that in addition 


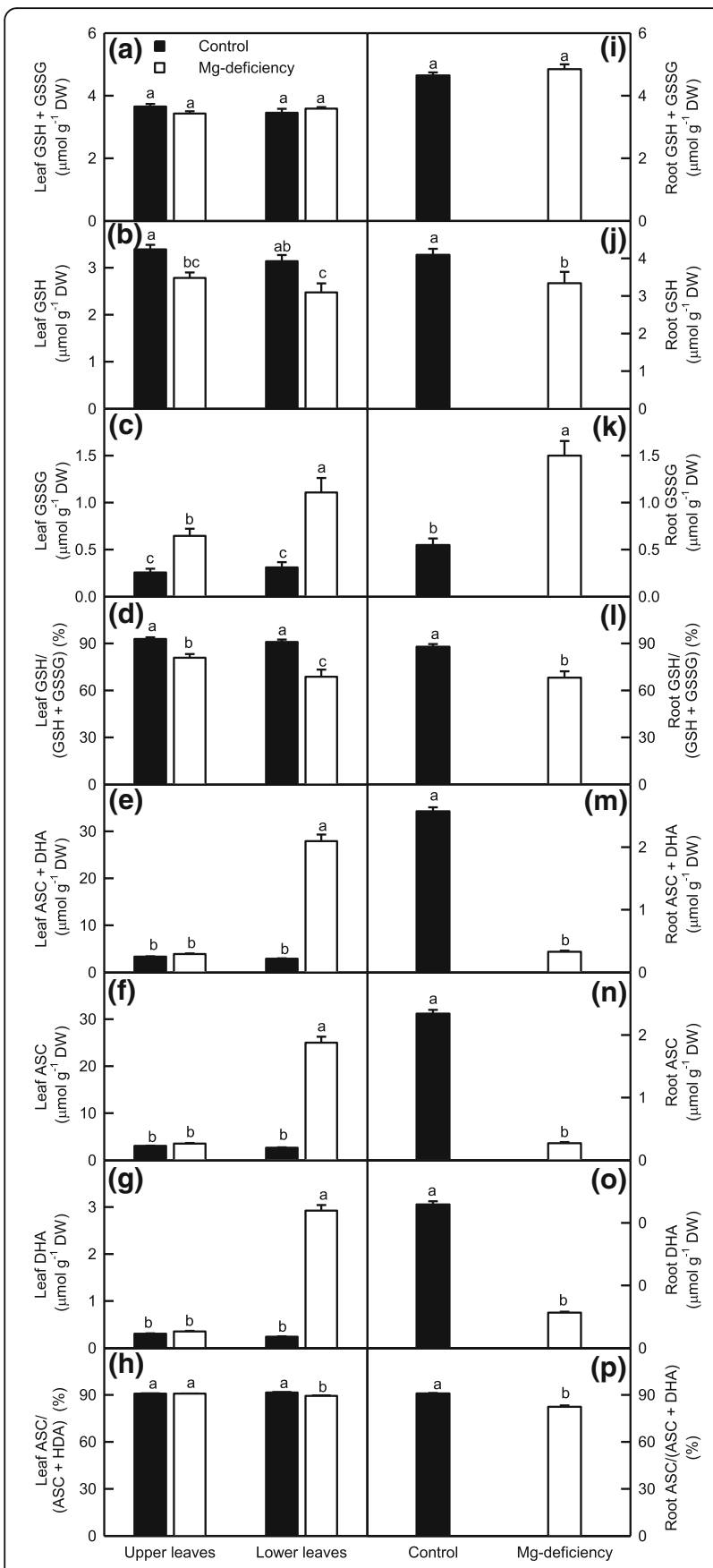

Fig. $8 \mathrm{Mg}$-deficient effects on GSH + GSSG (a, i $)$, GSH (b, j) and GSSG (c, k) concentrations, and GSH/(GSH + GSSG) ratio $(\mathbf{d}, \mathbf{l})$, and $\mathrm{ASC}+\mathrm{DHA}(\mathbf{e}, \mathbf{m}), \mathrm{ASC}(\mathbf{f}, \mathbf{n})$ and $\mathrm{DHA}(\mathbf{g}, \mathbf{o})$ concentrations, and $\mathrm{ASC} /(\mathrm{ASC}+\mathrm{DHA})$ ratio $(\mathbf{h}, \mathbf{p})$ in $\mathrm{C}$. sinensis leaves $(\mathbf{a}-\mathbf{h})$ and roots (i-p). Bars represent means $\pm \operatorname{SE}(n=8)$. Significant differences between $\mathrm{Mg}$-deficient roots and controls were made by unpaired $t$ test. Four means [two (Mg levels) $\times$ two (leaf positions)] were analyzed by two ANOVA followed by Duncan's new multiple range test. Different letters above the bars indicate a significant difference at $P<0.05$ to increased ROS production rate, the more pronounced lipid peroxidation in the Mg-deficient lower leaves could be explained by the larger increase in the MG concentration (Fig. 2). Regressive analysis indicated that leaf electrolyte leakage only displayed an increased trend with increasing MDA concentration, but increased linearly with increasing MG concentration (Table 1). MG is a potent reactive cytotoxin which can disrupt biomembrane structures and functions [35]. Kumar et al. [71] reported that transgenic tobacco plants overexpressing ALDRXV4 encoding an aldose reductase, which is involved in the convert of MG into acetol, had enhanced tolerance to drought and salinity by scavenging MG and lowering electrolyte leakage. Thus, the difference in the electrolyte leakage between the Mg-deficient lower and upper leaves could be at least partially explained by the larger increase in the MG level in the Mg-deficient lower leaves than that in the Mg-deficient upper leaves (Fig. 2).

Plants have evolved efficient enzymatic and non-enzymatic detoxification systems of ROS to protect plant cells from oxidative damage [18-20, 65]. In this study, the Mg-deficiency-induced increases in the activities of APX, MDHAR, DHAR, SOD and GuPX were greater in the Mg-deficient lower leaves and roots than those in the upper leaves (Fig. 4). The larger increases of antioxidant enzyme activities in the Mg-deficient lower leaves and roots than those in the Mg-deficient upper leaves agreed with the increased requirement for the removal of ROS (Fig. 3). The Mg-deficiency-induced upregulation of antioxidant enzymes have also been reported on many higher plants as mentioned in the background. It is a remarkable fact that among the six antioxidant enzymes, only the activity of CAT was decreased in the Mg-deficient leaves and roots (Fig. 4f, l, r and x). Similar results have been obtained on the $\mathrm{N}$-deficient grape leaves [18], B-stressed and Mg-deficient Citrus leaves [2, 14, 67, 72]. The larger decrease in CAT activity in the Mg-deficient lower leaves and roots than that in the Mg-deficient upper leaves might be related to the fact that CAT is very sensitive to oxidative stress [73, 74], and that the protein level of CAT can be decreased rapidly under conditions that inhibit translation such as salt, cold, high light, heat-shock or senescence [7476], because the production rates of superoxide anion and $\mathrm{H}_{2} \mathrm{O}_{2}$ were greatly increased in the $\mathrm{Mg}$-deficient lower leaves and roots, but slightly increased and significantly unaltered in the Mg-deficient upper leaves, respectively (Fig. 3).

As shown in Figs. 5-6, the activities of all the ten enzymes involved in S metabolism were significantly altered in the Mg-deficient lower leaves and roots, but kept unchanged in the Mg-deficient upper leaves except for slightly increased activity of ATPS on a DW or protein basis, and slightly decreased activities of APR on a DW or protein basis and of

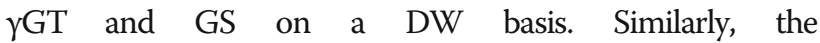
Mg-deficiency-induced alterations of (GSH + GSSG), GSH and GSSG concentrations and GSH/(GSH + GSSG) ratio 


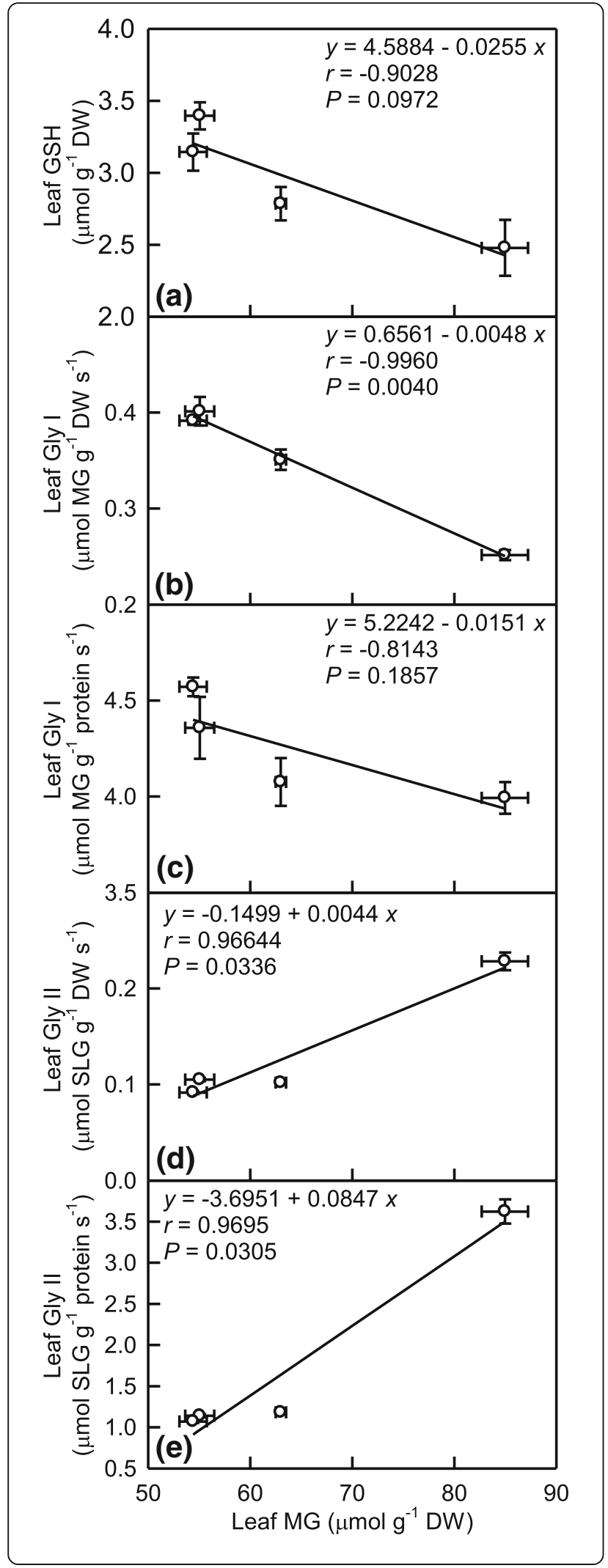

Fig. 9 MG concentration in relation to GSH concentration (a), Gly I (b-c) and Gly II (d-e) activities expressed on a DW (b and $\mathbf{d}$ ) or protein (c and $\mathbf{e}$ ) basis in C. sinensis leaves. Data are from Figs. 3, 7 and 8. Points represent means \pm SE $(n=8)$

were greater in the lower leaves and roots than those in the upper leaves (Fig. 8a-d and i-l). Obviously, the Mg-deficiency affected the thiol-based ROS detoxification system more in the lower leaves and roots than that in the upper leaves. This agreed with our data that the Mg-deficiency-induced of increases in ROS production rates and MDA accumulation were greater in the lower leaves and roots than those in the upper leaves (Fig. 3). The level of GSH in a given plant cell is the result of the coordinated actions of GSH biosynthesis, utilization and degradation [65]. CS converts sulfide to Cys, a key factor for GSH biosynthesis [77]. The biosynthesis of GSH from Cys is catalyzed by $\gamma$ GCS (a rate-limiting enzyme) and glutathione synthetase [78]. GS also participates in GSH biosynthesis via glutamate biosynthesis pathway [79]. The GSH formed can be utilized in diverse redox reactions to protect the plant cells against oxidative stress, thus leading to the oxidation of GSH to GSSG, which is reduced to GSH by GR [65]. For example, GIPX catalyzes mainly the conversion of $\mathrm{H}_{2} \mathrm{O}_{2}$ to $\mathrm{H}_{2} \mathrm{O}$ at the expense of $\mathrm{GSH}$, thereby producing GSSG [20,78]. GSTs catalyze the conjugation of a range of toxicants or their metabolites to GSH and thus lower their toxicity. Many GSTs have been shown to possess GIPX activity $[65,80]$. Evidence shows that $\gamma$ GT plays a key role in the degradation of GSH [81]. Therefore, the Mg-deficiency-induced decrease in GSH level might be caused by decreased biosynthesis due to decreased DW-based GS and/or CS activities and/or by the increased utilization due to increased DW-based GIPX activity (GST and GIPX activities) in the leaves (roots); the Mg-deficiency-induced increase of GSSG level might be caused by increased oxidation of GSH to GSSG due to increased activity of GIPX (GST and GIPX activities) in the lower leaves (roots) rather than by decreased reduction of GSSG to GSH by GR, whose activity was increased under $\mathrm{Mg}$-deficiency. However, the activities of GST, GR and GIPX were not significantly altered in the Mg-deficient upper leaves, the Mg-deficiency-induced increase of GSSG level in these leaves should be caused by other factors (Figs. 5-6). It is worth noting that MG is spontaneously converted to HTA using one molecule of GSH, that the resultant HTA is then catalyzed by Gly I and Gly II to lactate and one molecule of GSH is recycled back into the Gly system, and that the Gly system is involved in the maintenance of GSH homeostasis $[34,35]$. Thus, the Mg-deficiency-induced larger alterations of MG level and Gly system (Figs. 3e, j and 7) might also contribute to Mg-deficiency-induced larger decrease in GSH concentration in the lower leaves and roots than that in the upper leaves. 

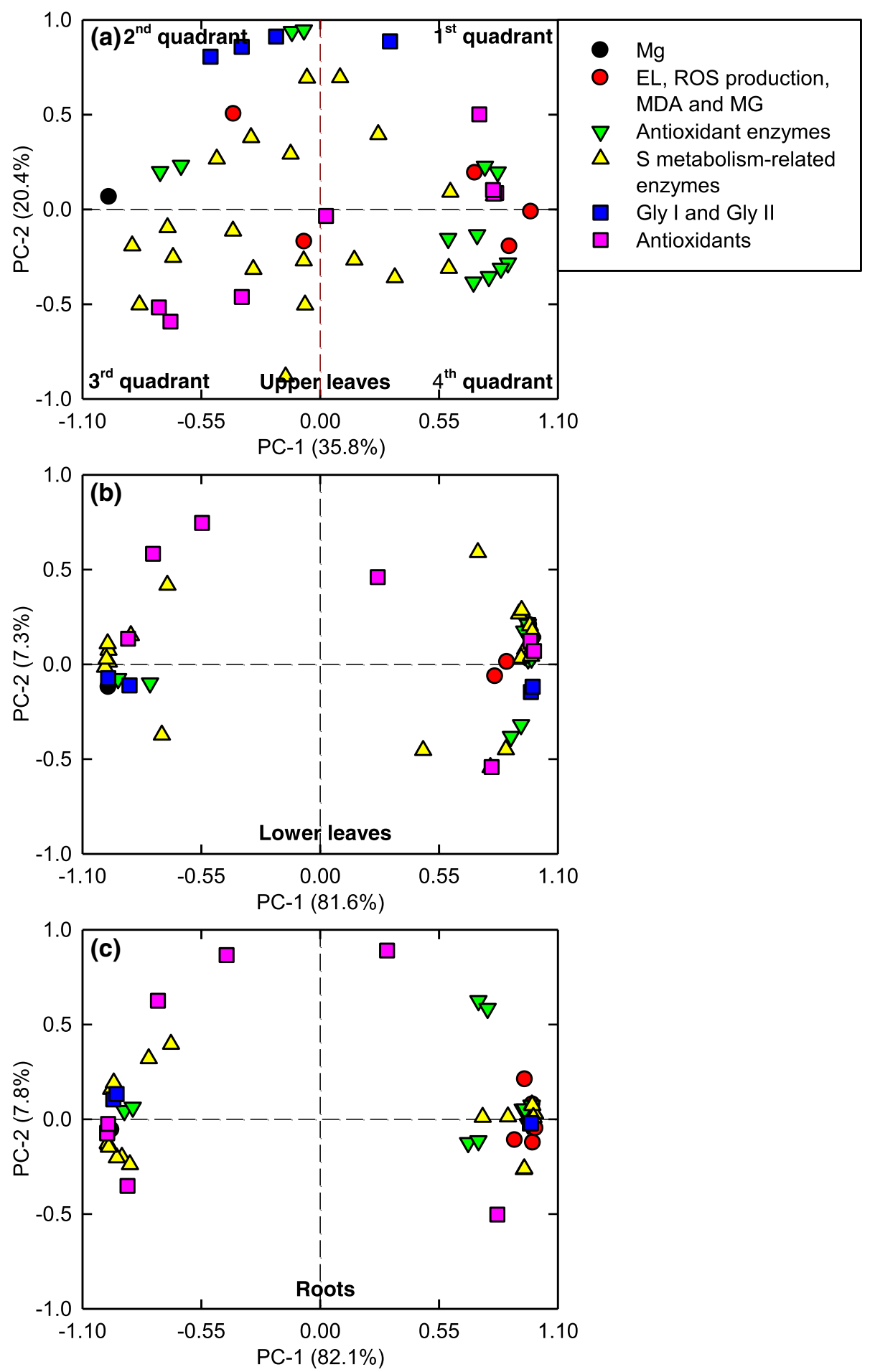

Fig. 10 PCA loading plots of physiological parameter in C. sinensis upper leaves (a), lower leaves (b) and roots (c)

Although the activities of most antioxidant and $\mathrm{S}$ metabolism-related enzymes and the concentration of GSH in the Mg-deficient leaves and roots and the concentration of ASC in the Mg-deficient leaves were kept in higher levels (Figs. 4-6 and 8), MDA concentration and/or electrolyte leakage were increased in the Mg-deficient lower and upper leaves and roots (Fig. 3a, $\mathrm{d}, \mathrm{f}$ and i). Therefore, the ROS detoxification systems as a whole did not protect effectively these $\mathrm{Mg}$-deficient leaves and roots from oxidative damage. This is also 


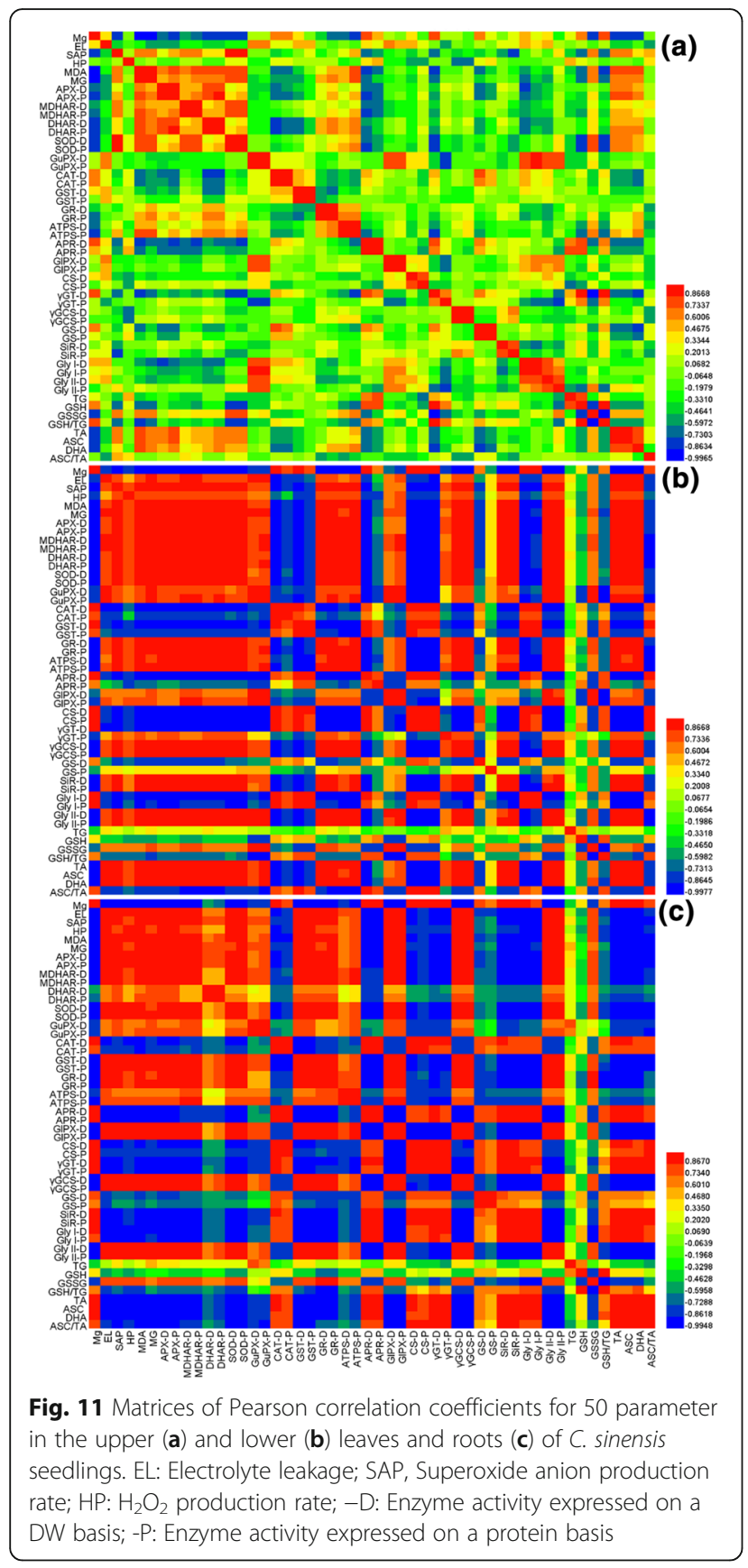

supported by our finding that the ratio of GSH to GSH + GSSG, which decreases under oxidative stress [82, 83], was decreased in the $\mathrm{Mg}$-deficient lower and upper leaves and roots (Fig. 8d and l).

\section{Possible causes for the Mg-deficiency-induced accumulation of MG in the leaves and roots}

The major route for the detoxification of MG is through the coordinated actions of Gly I and Gly II using GSH as a cofactor. GSH availability is very essential for the detoxification of MG [34, 35]. Our results showed that the
Mg-deficient lower leaves and roots had decreased activity of Gly I and increased activity of Gly II, but their activities remained unchanged in the Mg-deficient upper leaves except for a slight decrease in the DW-based Gly I activity (Fig. 7), and that the Mg-deficiency-induced decrease of GSH concentration was greater in the lower leaves and roots than that in the upper leaves (Fig. 8b and j). As shown in Fig. 9, leaf MG concentration increased linearly with decreasing DW-based Gly I activity, and had an increased trend with decreasing protein-based Gly I activity or GSH level; but increased linearly with increasing Gly II activity. Thus, the Mg-deficiency-induced increase of MG level in the Mg-deficient leaves and roots might be caused by the Mg-stimulated production of MG and the decreased MG detoxification capacity due to decreased GSH concentration (Fig. 8e and j) and Gly I activity on a DW and/or protein basis (Fig. 7a, c, e and g). In a word, the Gly system as a whole did not provide sufficient MG detoxification capacity to prevent the Mg-deficiency-induced production and accumulation of MG in the lower and upper leaves and roots.

\section{Some differences existed in the Mg-deficiency-induced alterations of ROS and MG metabolisms between the leaves and roots}

As shown in Fig. 12, Mg-deficiency affected gas exchange, Chl a fluorescence, and ROS and MG metabolisms more in the lower leaves than those in the upper leaves, but they displayed similar change patterns between Mg-deficient lower and upper leaves. By contrast, most of ROS and MG metabolism-related parameters had similar variation degrees and patterns between the Mg-deficient lower leaves and roots, but several parameters showed the opposite change trends. For example, the Mg-deficient lower leaves had a decreased GST activity and an increased SiR activity, but the reverse was this case for the Mg-deficient roots (Figs. 5-6). In addition, the concentrations of ASC + DHA, ASC and DHA were greatly increased in the Mg-deficient lower leaves (Fig. 8e-g), as previously obtained on the Mg-deficient Citrus leaves [2], but their concentrations were greatly reduced to low levels in the $\mathrm{Mg}$-deficient roots (Fig. 8m-o). PCA showed that the distributions of some parameters in the four quadrants were different (Fig. 10). Obviously, some differences existed in the Mg-deficiency-induced alterations of ROS and MG metabolisms between the lower leaves and roots. This is also supported by the different PCA correlation coefficients for parameters related to ROS and MG metabolisms in the lower leaves and roots (Fig. 11).

\section{Conclusions}

The Mg-deficiency-induced alterations of Mg level, gas exchange, Chl a fluorescence, and ROS and MG metabolisms were more pronounced in the lower leaves than 


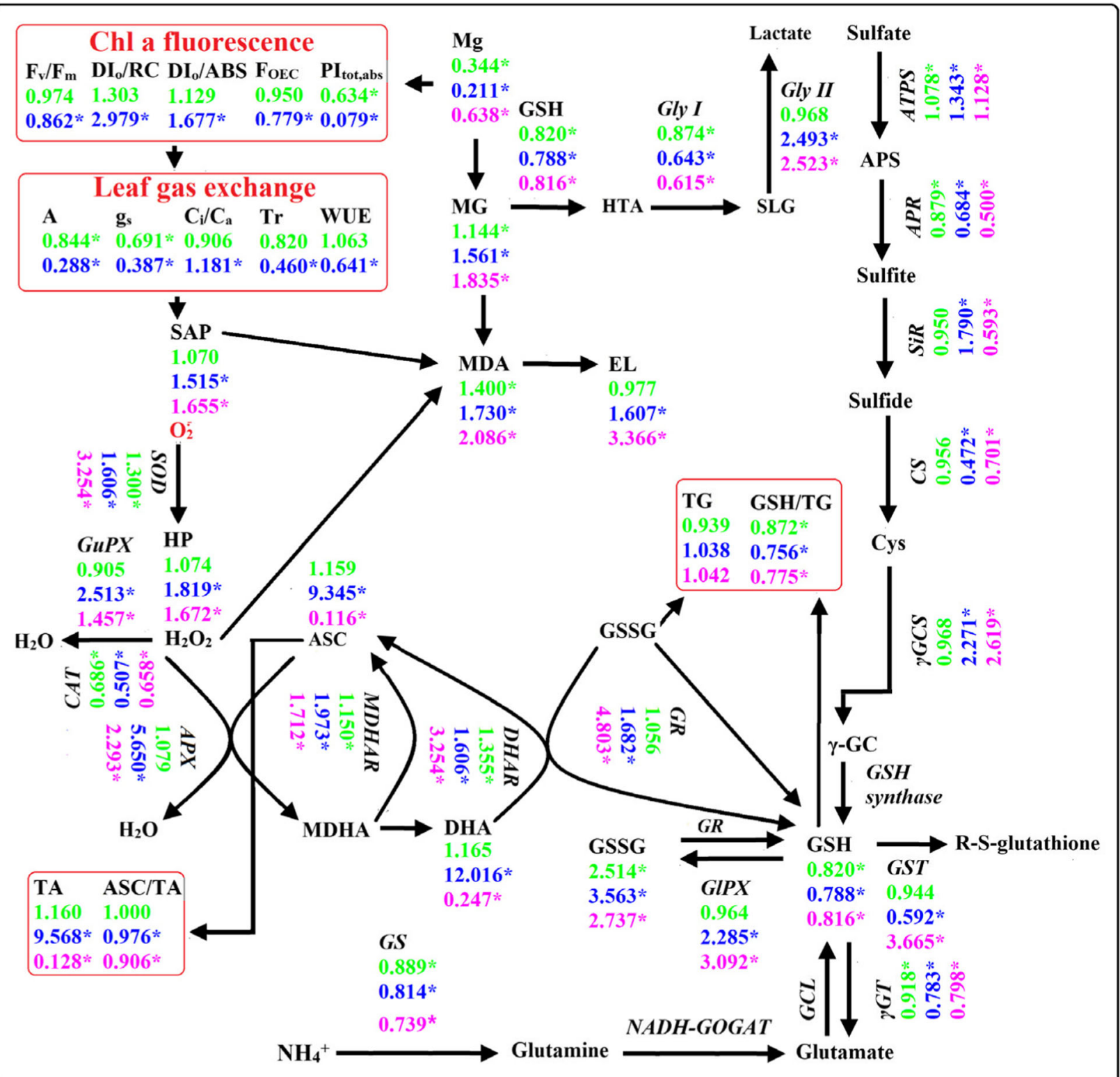

Fig. 12 A diagram showing the Mg-deficient effects on gas exchange, Chl a fluorescence parameters, ROS and MG metabolism in C. sinensis roots (magenta), lower (in blue) and upper (in green). In this Figure, we used italics for enzymes and plain format for metabolites. Data from Figs.1-8. Enzyme activities were expressed on a DW basis. Values were the ratios of Mg-deficiency to Mg-sufficiency. An asterisk indicates a significant difference between Mg-deficiency and Mg-sufficiency at $P<0.05$. An enzyme or metabolite was considered increased or decreased when it had both a relative change of more or less, respectively, than 1 and a $P$-value of $<0.05$. Metabolite concentrations or enzyme activities were assayed on a whole tissue extract and not on a subcellular level. GCL: Glutamate-cysteine ligase; $g_{s}$ : Stomatal conductance; NADH-GOGAT: NADH-dependent glutamine-2-oxoglutarate aminotransferase; $ү$ GC: $\gamma$-glutamylcysteine; TA: ASC + DHA; TG: GSH + GSSG; Tr: transpiration

those in the upper leave, but all the measured parameters showed similar change patterns between the Mg-deficient lower and upper leaves. This may be related to the fact that the transport of $\mathrm{Mg}$ from old leaves to the young leaves is improved under $\mathrm{Mg}$-deficient conditions in order to provide $\mathrm{Mg}$ for the normal growth and development of the young leaves. Accordingly, their differences between the lower and upper leaves were greatly intensified by Mg-deficiency. Most of ROS and MG metabolism-related parameters had similar variation degrees and trends between the Mg-deficient lower leaves and roots, but several parameters (i.e., GST, SiR, ASC + DHA, ASC and DHA) had the opposite variation trends. Obviously, some differences existed in the Mg-deficiency-induced alterations of ROS and MG metabolisms between the lower leaves and roots. The ROS 
and MG detoxification systems as a whole did not provide sufficient ROS and MG detoxification capacity to prevent the Mg-deficiency-induced production and accumulation of ROS and MG, thus leading to lipid peroxidation and the loss of plasma membrane integrity (increase of electrolyte leakage), especially in the lower leaves and roots.

\section{Additional files}

Additional file 1: Figure S1. Mg-deficiency effects on Citrus sinensis seedling growth (a) and Mg-deficient symptoms in the upper and lower leaves (b). Table S1. PCA for physiological parameters of upper leaves. Table S2. PCA for physiological parameters of lower leaves. Table S3. PCA for physiological parameters of roots. (DOCX $447 \mathrm{~kb}$ )

\section{Abbreviations}

APR: Adenosine 5'-phosphosulfate reductase; APX: Ascorbate peroxidase; ASC: Ascorbate; ATPS: ATP sulphurylase; CAT: Catalase; Chl: Chlorophyll; CS: Cysteine synthase; Cys: Cysteine; DHA: Dehydroascorbate; DHAR: DHA reductase; DI/ABS: Quantum yield for energy dissipation; DI/RC: Specific energy fluxes per reaction center for energy dissipation; DTT: Dithiothreitol; $F_{v} / F_{m}$ : Maximum PSII efficiency of dark-adapted leaves; GIPX: Glutathione peroxidase; Gly I: Glyoxalase I; Gly II: Glyoxalase II; GR: Glutathione reductase: GS: Glutamine synthetase; GSH: Reduced glutathione; GSSG: Oxidized glutathione; GST: Glutathione S-transferase; GuPX: Guaiacol peroxidase; MDA: Malondialdehyde; MDHA: Monodehydroascorbate; MDHAR: MDHA reductase; Mg: Magnesium; MG: Methylglyoxal; OA: Organic acid; OAS: Oacetyl-L-serine; OEC: Oxygen-evolving complex; OJIP transient: Chl a fluorescence transient; PItotabs: Total performance index; PSII: Photosystem II; RC: Reaction center; ROS: Reactive oxygen species; SiR: Sulfite reductase; SLG: S-D-lactoylglutathione; SOD: Superoxide dismutase; TCA: Trichloroacetic acid; WUE: Water use efficiency; $\gamma G C S$ : $\gamma$-glutamylcysteine synthase; $\gamma \mathrm{GT}$ : $\gamma^{-}$ glutamyltransferase

\section{Acknowledgements}

Not applicable.

\section{Funding}

This study was financially supported by the National Natural Science Foundation of China (No. 31572081), the Provincial Natural Science Foundation of Fujian, China (No. 2016 J01115), and the Special Fund for Scientific and Technological Innovation of Fujian Agriculture and Forestry University (No.CXZX2017358). The funders had no role in the design of the study and collection, analysis, and interpretation of data and in writing the manuscript.

\section{Availability of data and materials}

All data analyzed in this study are included in this published article and its additional files.

\section{Authors' contributions}

$Y C$ carried out most of the experiment, analyzed the data, and drafted the manuscript; $\mathrm{HZ}, \mathrm{XY}$ and $\mathrm{ZH}$ participated in the measurements of leaf gas exchange, $\mathrm{Mg}$ and data analysis; $Y Q$ participated in the direction of this study; JG participated in the measurements of enzymes and data analysis; LC and $L Y$ designed and directed the study and revised the manuscript. All authors have read and approved the final manuscript.

\section{Ethics approval and consent to participate}

Citrus sinensis seeds, which were public and available for non-commercial purpose, were collected from Minan village, Tingjiang town, Mawei district, Fuzhou city, China. Collection of seeds complied with the institutional, national and international guidelines. No specific permits were required.

\section{Consent for publication}

Not applicable.

\section{Competing interests}

The authors declare that they have no competing interests. The author LiSong Chen is an Associate Editor of BMC Plant Biology.

\section{Publisher's Note}

Springer Nature remains neutral with regard to jurisdictional claims in published maps and institutional affiliations.

\section{Author details}

'Institute of Plant Nutritional Physiology and Molecular Biology, College of Resources and Environment, Fujian Agriculture and Forestry University, Fuzhou 350002, China. ${ }^{2}$ Institute of Materia Medica, Fujian Academy of Medical Sciences, Fuzhou 350001, China. ${ }^{3}$ Key Lab of Soil Ecosystem Health and Regulation, Fujian Province University, Fujian Agriculture and Forestry University, Fuzhou 350002, China. ${ }^{4}$ The Higher Educational Key Laboratory of Fujian Province for Soil Ecosystem Health and Regulation, College of Resources and Environment, Fujian Agriculture and Forestry University, Fuzhou 350002, China.

Received: 18 January 2019 Accepted: 11 February 2019

Published online: 15 February 2019

\section{References}

1. Cakmak I, Kirkby EA. Role of magnesium in carbon partitioning and alleviating photooxidative damage. Physiol Plant. 2008;133:692-704.

2. Yang GH, Yang LT, Jiang HX, Wang P, Chen LS. Physiological impacts of magnesium-deficiency in Citrus seedlings: photosynthesis, antioxidant system and carbohydrates. Trees Struct Funct. 2012;26:1237-50.

3. Li CP, Qi YP, Zhang J, Yang LT, Wang DD, Ye X, Lai NW, Tan LL, Lin D, Chen LS. Magnesium-deficiency-induced alterations of gas exchange, major metabolites and key enzymes differ among roots, lower and upper leaves of Citrus sinensis seedlings. Tree Physiol. 2017;37:1564-81.

4. Jin XL, Ma CL, Yang LT, Chen LS. Alterations of physiology and gene expression due to long-term magnesium-deficiency differ between leaves and roots of Citrus reticulata. J Plant Physiol. 2016;198:103-15.

5. Fischer ES, Bremer E. Influence of magnesium deficiency on rates of leaf expansion, starch and sucrose accumulation, and net assimilation in Phaseolus vulgaris. Physiol Plant. 1993;89:271-6.

6. Fischer ES, Lohaus G, Heineke D, Heldt HW. Magnesium deficiency results in accumulation of carbohydrates and amino acids in source and sink leaves of spinach. Physiol Plant. 1998;102:16-20.

7. Yang LT, Yang GH, You X, Zhou CP, Lu YB, Chen LS. Magnesium deficiencyinduced changes in organic acid metabolism of Citrus sinensis roots and leaves. Biol Plant. 2013;57:481-6.

8. Cakmak I, Yazici AM. Magnesium: a forgotten element in crop production. Better Crops. 2010;94:23-5.

9. Morton AR, Trolove SN, Kerckhoffs LHJ. Magnesium deficiency in Citrus grown in the Gisborne district of New Zealand. New Zeal J Crop Hort Sci. 2008;36:199-213.

10. Guo W, Hussain H, Liang Z, Yang D. Magnesium deficiency in plants: an urgent problem. Crop J. 2016;4:83-91.

11. Ling $L L$, Peng $L Z$, Cao L, Jiang $C L$, Chun CP, Zhang GY, Wang ZX. Effect of magnesium deficiency on photosynthesis characteristic of Beibei 447 Jinchen orange. J Fruit Sci. 2009;26:275-80.

12. Li Y, Han MQ, Lin F, Ten Y, Lin J, Zhu DH, Guo P, Weng YB, Chen LS. Soil chemical properties, 'Guanximiyou' pummelo leaf mineral nutrient status and fruit quality in the southern region of Fujian province. China J Soil Sci Plant Nutr. 2015;15:615-28.

13. Hermans $C$, Verbruggen $N$. Physiological characterization of magnesium deficiency in Arabidopsis thaliana. J Exp Bot. 2005;56:2153-61.

14. Tang N, Li Y, Chen LS. Magnesium deficiency-induced impairment of photosynthesis in leaves of fruiting Citrus reticulata trees accompanied by up-regulation of antioxidant metabolism to avoid photooxidative damage. $J$ Plant Nutr Soil Sci. 2012;175:784-93.

15. Cakmak I, Hengeler C, Marschner H. Partitioning of shoot and root dry matter and carbohydrates in bean plants suffering from phosphorus, potassium and magnesium deficiency. J Exp Bot. 1994;45:1245-50.

16. da Silva DM, Brandão IR, Alves JD, de Santos MO, de Souza KRD, de Silveira HRO. Physiological and biochemical impacts of magnesium-deficiency in two cultivars of coffee. Plant Soil. 2014;382:133-50. 
17. Ceylan Y, Kutman UB, Mengutay M, Cakmak I. Magnesium applications to growth medium and foliage affect the starch distribution, increase the grain size and improve the seed germination in wheat. Plant Soil. 2016;406:145-56.

18. Chen LS, Cheng L. Both xanthophyll cycle-dependent thermal dissipation and the antioxidant system are upregulated in grape (Vitislabrusca L. CV. Concord) leaves in response to N limitation. J Exp Bot. 2003:54:2165-75.

19. Guo P, Li Q, Qi YP, Yang LT, Ye X, Chen HH, Chen LS. Sulfur-mediatedalleviation of aluminum-toxicity in Citrus grandis seedlings. Int J Mol Sci. 2017;18:2570.

20. Guo P, Qi YP, Cai YT, Yang TY, Yang LT, Huang ZR, Chen LS. Aluminum effects on photosynthesis, reactive oxygen species and methylglyoxal detoxification in two Citrus species differing in aluminum tolerance. Tree Physiol. 2018;38:1548-65.

21. Manna P, Sinha M, Sil PC. Arsenic-induced oxidative myocardial injury: protective role of arjunolic acid. Arch Toxicol. 2008;82:137-49.

22. Cakmak I. Activity of ascorbate-dependent $\mathrm{H}_{2} \mathrm{O}_{2}$-scavenging enzymes and leaf chlorosis are enhanced in magnesium- and potassium-deficient leaves, but not in phosphorus-deficient leaves. J Exp Bot. 1994;45:1259-66.

23. Cakmak I, Marschner H. Magnesium deficiency and high light intensity enhance activities of superoxide dismutase, ascorbate peroxidase, and glutathione reductase in bean leaves. Plant Physiol. 1992;98:1222-7.

24. Tewari PK, Kumar P, Tewari N, Srivastava S, Sharma PN. Macronutrient deficiencies and differential antioxidant responses-influence on the activity and expression of superoxide dismutase in maize. Plant Sci. 2004;166:687-94.

25. Mengutay M, Ceylan Y, Kutman UB, Cakmak I. Adequate magnesium nutrition mitigates adverse effects of heat stress on maize and wheat. Plant Soil. 2013;368:57-72.

26. Tewari PK, Kumar P, Sharma PN. Magnesium deficiency induced oxidative stress and antioxidant responses in mulberry plants. Sci Hort. 2006;108:7-14.

27. Ding YC, Chang CR, Luo W, Wu YS, Ren XL, Wang P, Wu GH. High potassium aggravates the oxidative stress induced by magnesium deficiency in rice leaves. Pedosphere. 2008;18:316-27.

28. Chou TS, Chao YY, Huang WD, Hong CY, Kao CH. Effect of magnesium deficiency on antioxidant status and cadmium toxicity in rice seedlings. J Plant Physiol. 2011;168:1021-30.

29. Anza M, Riga P, Garbisu C. Time course of antioxidant responses of Capsicum annuum subjected to a progressive magnesium deficiency. Ann Appl Biol. 2005;146:123-34

30. Capaldi FR, Gratão PL, Reis AR, Lima LW, Azevedo RA. Sulfur metabolism and stress defense responses in plants. Trop Plant Biol. 2015;8(3-4):60-73.

31. Koprivova A, Suter M, Op den camp R, Brunold C, Kopriva S. Regulation of sulfate assimilation by nitrogen in Arabidopsis. Plant Physiol 2000;122:737746.

32. Kopriva S, Hartmann T, Massaro G, Hönicke P, Rennenberg H. Regulation of sulfate assimilation by nitrogen and sulfur nutrition in poplar trees. Trees Struct Funct. 2004;18:320-6.

33. Muneer S, Lee BR, Kim KY, Park SH, Zhang Q, Kim TH. Involvement of sulphur nutrition in modulating iron deficiency responses in photosynthetic organelles of oilseed rape (Brassica napus L.). Photosynth Res. 2014;119:319329.

34. Li ZG. Methylglyoxal and glyoxalase system in plants: old players, new concepts. Bot Rev. 2016;82:183-203.

35. Hasanuzzaman M, Nahar K, Hossain MS, Mahmud JA, Rahman A, Inafuku M, Oku H, Fujita M. Coordinated actions of glyoxalase and antioxidant defense systems in conferring abiotic stress tolerance in plants. Int J Mol Sci. 2017; 18:200.

36. Yadav SK, Singla-Pareek SL, Ray M, Reddy MK, Sopory SK. Transgenic tobacco plants overexpressing glyoxalase enzymes resist an increase in methylglyoxal and maintain higher reduced glutathione levels under salinity stress. FEBS Let. 2005;579:6265-71.

37. Peng HY, Qi YP, Lee J, Yang LT, Guo P, Jiang HX, Chen LS. Proteomic analysis of Citrus sinensis roots and leaves in response to long-term magnesium-deficiency. BMC Genomics. 2015;16:253.

38. Billard V, Maillard A, Coquet L, Jouenne T, Cruz F, Garcia-Mina JM, Yvin JC, Ourry A, Etienne P. Mg deficiency affects leaf mg remobilization and the proteome in Brassica napus. Plant Physiol Biochem. 2016;107:337-43.

39. Jezek M, Geilfus CM, Mühling KH. Glutamine synthetase activity in leaves of Zea mays $L$ as influenced by magnesium status. Planta. 2015;242:1309-19.

40. Wang $H$, Chu T. Effect of mg deficiency on plasma membrane permeability, membrane lipid peroxidation and endogenous oxygen radicals scavenging enzymes systems in common bean. Plant Nutr Fer Sci. 1998;4:386-92.
41. Riga P, Anza M, Garbisu C. Suitability of the antioxidative system as marker of magnesium deficiency in Capsicum annuum L. plants under controlled conditions. Plant Growth Regul. 2005;46:51-9.

42. Candan N, Tarhan L. Relationship among chlorophyll-carotenoid content, antioxidant enzyme activities and lipid peroxidation levels by $\mathrm{Mg}^{2+}$ deficiency in the Mentha pulegium leaves. Plant Physiol Biochem. 2003;41:35-40.

43. Chapman HD. The mineral nutrition of Citrus. In: Reuther W, Webber HJ, Batchelor LD, editors. The Citrus industry, Vol. 2. California, CA: Division of Agricultural Sciences, University of California; 1968. p. 127-189.

44. Verbruggen $\mathrm{N}$, Hermans $\mathrm{C}$. Physiological and molecular responses to magnesium nutritional imbalance in plants. Plant Soil. 2013;368:87-99.

45. Lasa B, Frechilla S, Aleu M, González-Moro B, Lamsfus C, Aparicio-Tejo PM. Effects of low and high levels of magnesium on the response of sunflower plants grown with ammonium and nitrate. Plant Soil. 2000; 225:167-74

46. Yang $N$, Jiang J, Xie H, Bai M, Xu Q, Wang X, Yu X, Chen Z, Guan Y. Metabolomics reveals distinct carbon and nitrogen metabolic responses to magnesium deficiency in leaves and roots of soybean [Glycine max (Linn.) Merr.]. Front. Plant Sci. 2017:8:2091.

47. Huang JH, Xu J, Ye X, Luo TY, Ren LH, Fan GC, Qi YP, Li Q, Ferarezi RS, Chen LS. Magnesium deficiency affects secondary lignification of the vascular system in Citrus sinensis seedlings. Trees Struct Funct. 2019;33: 171-82.

48. Hermans C, Vuylsteke M, Coppens F, Craciun A, Inzé D, Verbruggen N. Early transcriptomic changes induced by magnesium deficiency in Arabidopsis thaliana reveal the alteration of circadian clock gene expression in roots and the triggering of abscisic acid-responsive genes. New Phytol. 2010;187: 119-31.

49. Hermans C, Vuylsteke M, Coppens F, Cristescu SM, Harren FJ, Inzé D, Verbruggen $\mathrm{N}$. Systems analysis of the responses to long-term magnesium deficiency and restoration in Arabidopsis thaliana. New Phytol. 2010;187: 132-44.

50. Ma CL, Qi YP, Yang LT, Lu YB, Guo P, Ye X, Chen LS. MicroRNA regulatory mechanisms on Citrus sinensis leaves to magnesium-deficiency. Front Plant Sci. 2016;7:201.

51. Liang WW, Huang JH, Li CP, Yang LT, Ye X, Lin D, Chen LS. MicroRNAmediated responses to long-term magnesium-deficiency in Citrus sinensis roots revealed by Illumina sequencing. BMC Genomics. 2017;18:657.

52. Jiang HX, Chen LS, Zheng JG, Han S, Tang N, Smith BR. Aluminum-induced effects on photosystem II photochemistry in Citrus leaves assessed by the chlorophyll a fluorescence transient. Tree Physiol. 2008;28:1863-71.

53. Liao XY, Yang LT, Lu YB, Ye X, Chen LS. Roles of rootstocks and scions in aluminum-tolerance of Citrus. Acta Physiol Plant. 2015;37:1743.

54. Long A, Zhang J, Yang LT, Ye X, Lai NW, Tan LL, Lin D, Chen LS. Effects of low $\mathrm{pH}$ on photosynthesis, related physiological parameters and nutrient profile of Citrus. Front Plant Sci. 2017;8:185.

55. Chen LS, Qi YP, Liu XH. Effects of aluminum on light energy utilization and photoprotective systems in Citrus leaves. Ann Bot. 2005;96:35-41.

56. Bradford MM. A rapid and sensitive method for quantitation of microgram quantities of protein utilizing the principle of protein-dye binding. Anal Biochem. 1976;72:248-54.

57. Hodges DM, DeLong JM, Forney CF, Prange RK. Improving the thiobarbituric acid-reactive-substances assay for estimating lipid peroxidation in plant tissues containing anthocyanin and other interfering compounds. Planta. 1999;207:604-11.

58. Wild R, Ooi L, Srikanth V, Münch G. A quick, convenient and economical method for the reliable determination of methylglyoxal in millimolar concentrations: the N-acetyl-L-cysteine assay. Anal Bioanal Chem. 2012;403: 2577-81.

59. Giannopolitis CN, Ries SK. Superoxide dismutases I. Occurrence in higher plants. Plant Physiol. 1977;59:309-14.

60. Chen LS, Li P, Cheng L. Effects of high temperature coupled with high light on the balance between photooxidation and photoprotection in the sunexposed peel of apple. Planta. 2008;228:745-56.

61. Lappartient AG, Touraine B. Demand-driven control of root ATP sulfurylase activity and $\mathrm{SO}_{4}{ }^{2}$-uptake in intact canola: the role of phloem-translocated glutathione. Plant Physiol. 1996;111:147-57.

62. Warrilow AG, Hawkesford MJ. Cysteine synthase (O-acetylserine (thiol) lyase) substrate specificities classify the mitochondrial isoform as a cyanoalanine synthase. J Exp Bot. 2000;51:985-93. 
63. Trüper HG, Rogers LA. Purification and properties of adenylyl sulfate reductase from the phototrophic sulfur bacterium Thiocapsa roseopersicina. J Bacteriol. 1971;108:1112-21.

64. Ostrowski J, Barber MJ, Rueger DC, Miller BE, Siegel LM, Kredich NM. Characterization of the flavoprotein moieties of NADPH-sulfitereductase from Salmonella typhimurium and Escherichia coli. Physicochemical and catalytic properties, amino acid sequence deduced from DNA sequence of cysJ, and comparison with NADPH-cytochrome P-450 reductase. J Biol Chem. 1989;264:15796-808.

65. Mishra S, Srivastava S, Tripathi RD, Trivedi PK. Thiol metabolism and antioxidant systems complement each other during arsenate detoxification in Ceratophyllum demersum L. Aquat Toxicol. 2008;86:205-15.

66. Hasanuzzaman M, Hossain MA, Fujita M. Nitric oxide modulates antioxidant defense and the methylglyoxal detoxification system and reduces salinityinduced damage of wheat seedlings. Plant Biotechnol Rep. 2011;5:353-65.

67. Han S, Chen LS, Jiang HX, Smith BR, Yang LT, Xie CY. Boron deficiency decreases growth and photosynthesis, and increases starch and hexoses in leaves of Citrus seedlings. J Plant Physiol. 2008;165:1331-41.

68. Hawkesford M, Horst W, Kichey T, Lambers H, Schjoerring J, Møller IS, White P. Functions of macronutrients. In: Marschner P, editor. Marschner's mineral nutrition of higher plants. 3rd ed. CA: Elsevier/Academic Press; 2012. p. 135-89.

69. Hernandez M, Fernandez-Garcia N, Garcia-Garma J, Rubio-Asensio JS, Rubio F, Olmos E. Potassium starvation induces oxidative stress in Solanum lycopersicum L. roots. J Plant Physiol. 2012;169:1366-74.

70. Höller S, Meyer A, Frei M. Zinc deficiency differentially affects redox homeostasis of rice genotypes contrasting in ascorbate level. J Plant Physiol. 2014;171:1748-56.

71. Kumar D, Singh P, Yusuf MA, Upadhyaya CP, Roy SD, Hohn T, Sarin NB. The Xerophyta viscosa aldose reductase (ALDRXV4) confers enhanced drought and salinity tolerance to transgenic tobacco plants by scavenging methylglyoxal and reducing the membrane damage. Mol Biotechnol. 2013; 54:292-303.

72. Han S, Tang N, Jiang HX, Yang LT, Li Y, Chen LS. CO 2 assimilation, photosystem II photochemistry, carbohydrate metabolism and antioxidant system of Citrus leaves in response to boron stress. Plant Sci. 2009;176:14353.

73. Escobar JA, Rubio MA, Lissi EA. SOD and catalase inactivation by singlet oxygen and peroxyl radicals. Free Radic Biol Med. 1996;20:285-90.

74. Orendi G, Zimmermann P, Baar C, Zentgraf U. Loss of stress-induced expression of catalase 3 during leaf senescence in Arabidopsis thaliana is restricted to oxidative stress. Plant Sci. 2001;161:301-14.

75. Schmidt M, Dehne S, Feierabend J. Post-transcriptional mechanisms control catalase synthesis during its light-induced turnover in rye leaves through the availability of the hemin cofactor and reversible changes of the translation efficiency of mRNA. Plant J. 2002;31:601-13.

76. Mhamdi A, Queval G, Chaouch S, Vanderauwera S, Van Breusegem F, Noctor G. Catalase function in plants: a focus on Arabidopsis mutants as stressmimic models. J Exp Bot. 2010;61:4197-220.

77. Kopriva S, Rennenberg $\mathrm{H}$. Control of sulfate assimilation and glutathione synthesis: interaction with N and C metabolism. J Exp Bot. 2004:55:1831-42.

78. Noctor $\mathrm{G}$, Foyer $\mathrm{CH}$. Ascorbate and glutathione: keeping active oxygen under control. Annu Rev Plant Physiol Plant Mol Biol. 1998;49:249-79.

79. Hossain Z, Hajika M, Komatsu S. Comparative proteome analysis of high and low cadmium accumulating soybeans under cadmium stress. Amino Acids. 2012:43:2393-416.

80. Roxas VP, Smith JRK, Allen ER, Allen RD. Overexpression of glutathione Stransferase/glutathioneperoxidase enhances the growth of transgenic tobacco seedlings during stress. Nat Biotech. 1997;15:988-91.

81. Storozhenko S, Belles-Boix E, Babiychuk E, Hérouart D, Davey MW, Slooten L, Van Montagu M, Inzé D, Kushnir S. Y-Glutamyl transpeptidase in transgenic tobacco plants. Cellular localization, processing, and biochemical properties. Plant Physiol. 2002;128:1109-19.

82. Law MY, Charles SA, Halliwell B. Glutathione and ascorbic acid in spinach (Spinacia oleracea) chloroplasts. The effect of hydrogen peroxide and of paraquat. Biochem J. 1983;210:899-903.

83. Gossett DR, Millhollon EP, Lucas MC. Antioxidant responses to $\mathrm{NaCl}$ stress in salt-tolerant and salt-sensitive cultivars of cotton. Crop Sci. 1994;34:706-14.

\section{Ready to submit your research? Choose BMC and benefit from:}

- fast, convenient online submission

- thorough peer review by experienced researchers in your field

- rapid publication on acceptance

- support for research data, including large and complex data types

- gold Open Access which fosters wider collaboration and increased citations

- maximum visibility for your research: over $100 \mathrm{M}$ website views per year

At BMC, research is always in progress.

Learn more biomedcentral.com/submissions 